Prepared for the U.S. Department of Energy under Contract DE-AC05-76RL01830

\title{
PNNL Stress/Strain Correlation for Zircaloy
}

\author{
KJ Geelhood CE Beyer \\ WG Luscher
}

July 2008

\section{Pacific Northwest}




\title{
DISCLAIMER
}

This report was prepared as an account of work sponsored by an agency of the United States Government. Neither the United States Government nor any agency thereof, nor Battelle Memorial Institute, nor any of their employees, makes any warranty, express or implied, or assumes any legal liability or responsibility for the accuracy, completeness, or usefulness of any information, apparatus, product, or process disclosed, or represents that its use would not infringe privately owned rights. Reference herein to any specific commercial product, process, or service by trade name, trademark, manufacturer, or otherwise does not necessarily constitute or imply its endorsement, recommendation, or favoring by the United States Government or any agency thereof, or Battelle Memorial Institute. The views and opinions of authors expressed herein do not necessarily state or reflect those of the United States Government or any agency thereof.

\author{
PACIFIC NORTHWEST NATIONAL LABORATORY \\ operated by \\ BATTELLE \\ for the \\ UNITED STATES DEPARTMENT OF ENERGY \\ under Contract DE-AC05-76RL01830
}

Printed in the United States of America
Available to DOE and DOE contractors from the Office of Scientific and Technical Information,
P.O. Box 62, Oak Ridge, TN 37831-0062;
ph: (865) 576-8401
fax: $(865)$ 576-5728
email: reports@adonis.osti.gov

\begin{abstract}
Available to the public from the National Technical Information Service, U.S. Department of Commerce, 5285 Port Royal Rd., Springfield, VA 22161 ph: (800) 553-6847 fax: $(703) 605-6900$ email: orders@ntis.fedworld.gov online ordering: http://www.ntis.gov/ordering.htm
\end{abstract}

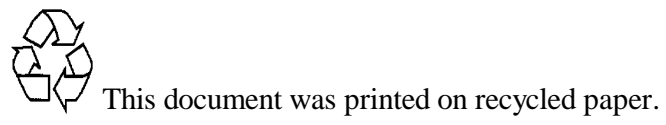




\section{PNNL Stress/Strain Correlation for Zircaloy}

KJ Geelhood CE Beyer

WG Luscher

July 2008

Prepared for the US Nuclear Regulatory Commission Division of Spent Fuel Storage and Transportation 


\section{Introduction}

Pacific Northwest National Laboratory (PNNL) was tasked with incorporating cladding mechanical property data into the Nuclear Regulatory Commission (NRC) fuel codes, FRAPCON- ${ }^{1}$ and FRAPTRAN ${ }^{2}$, by the NRC Office of Nuclear Reactor Research. The objective of that task was to create a mechanical model that can calculate true stress, true strain, and the possible failure of the fuel rod cladding based on uniaxial test data. The fitted coefficients of the mechanical models are based on data from uniaxial tests (or biaxial tests normalized to a uniaxial stress state) that measure yield strength, ultimate tensile strength and uniform elongation as well as engineering stress/strain curves when available. The models described here apply only to cladding with circumferential hydrides and do not apply to cladding with radial hydrides or significant hydride blisters or spalling.

After this model was developed, PNNL was tasked by the NRC Division of Spent Fuel Storage and Transportation (SFST) to compile this report that presents the mechanical property model, model to data comparisons, and discusses how these models can be applied to spent fuel cladding analyses.

Presented in this report are the results of using the data that were compiled by PNNL from the open literature at the beginning of June 2004 with the exception of experimental data recently collected by and received from Argonne National Laboratory (ANL) for modeling and comparisons against these data. The mechanical property data is primarily from cold work stress relief annealed (SRA) Zircaloy-4 (material used for PWR cladding) while only a small amount of mechanical property data was found from recrystallized (RXA) Zircaloy-2 (primarily the material used for BWR cladding) with the latter material having little data at high burnup levels.

The PNNL database consists of yield and ultimate tensile strengths, uniform and total strain, local fast fluence, local burnup, oxide thickness, hydrogen concentrations, test temperature, strain rate, and cold work ratio for each specimen. Information on coldwork level is many times not expressly given and, therefore, was estimated from information provided on fabrication. Other available data come from the PROMETRA program $^{25}$ and consist of high burnup cladding yield and ultimate tensile strengths as a function of temperature and strain rate with limited information on corrosion and hydrogen levels.

The PNNL database of yield strength, ultimate tensile strength and uniform elongation consists of approximately 270 uniaxial tube tension tests ${ }^{3-18}, 150$ biaxial burst tests ${ }^{3-5,8,9}$, $10,12,13,19-21$, and $180^{6,8,12,13,22-24}$ ring stretch tests. The temperature, strain rate, and fast fluences of these data ranged from $293 \mathrm{~K}$ to $750 \mathrm{~K}\left(68^{\circ} \mathrm{F}-890^{\circ} \mathrm{F}\right), 2 \times 10^{-6}$ to $4 \times 10^{-3} \mathrm{in} / \mathrm{in} / \mathrm{s}$, and 0.0 to $1.4 \times 10^{26} \mathrm{n} / \mathrm{m}^{2}(\mathrm{E}>1 \mathrm{MeV})$, respectively. The data from References 6 and 9 have recently been added to this database. 
The PROMETRA database ${ }^{25}$ from Commissariat à l'Energie Atomique (CEA) consists of 105 ring stretch and axial tension tests on cladding over the temperature, strain rate, and fast fluence ranges of $293 \mathrm{~K}$ to $1273 \mathrm{~K}\left(68^{\circ} \mathrm{F}-1832^{\circ} \mathrm{F}\right), 0.01$ to $5 \mathrm{in} / \mathrm{in} / \mathrm{s}$, and $6 \times 10^{25}$ to $1.2 \times 10^{26} \mathrm{n} / \mathrm{m}^{2}(\mathrm{E}>1 \mathrm{MeV})$, respectively. However, PNNL only has a plot of these data as a function of temperature and does not have a tabulation of each individual data point. As a result, the PROMETRA data are not tabulated over the entire range of the PNNL database. However, the PROMETRA data were used to determine the strain rate and temperature dependence above $4 \times 10^{-3} / \mathrm{s}$ and $673 \mathrm{~K}$ because this range of data is lacking in the PNNL database.

Since the development of this model, new mechanical property data have become available $^{29,31-33}$. The models described in this report were developed using data from axial tension tests and biaxial burst tests from the PNNL database, and validated with data from ring stretch tests from the PNNL database and with the more recent data from axial tensile tests and ring stretch tests.

The uniaxial tension test data from the PNNL database were used directly as measured, since these tests are for a uniaxial stress state, i.e., $\sigma_{\text {hoop }}=\sigma_{\text {radial }}=0$. The biaxial burst test data from the PNNL database were adjusted down by multiplying by a factor of $\sqrt{3} / 2$ as predicted by the von Mises failure criteria ${ }^{26}$ for this biaxial stress state, where $\sigma_{\text {axial }}=2 \sigma_{\text {hoop. }}$. The ring test data can be used as measured, however, it has been demonstrated that a large degree of scatter exists in the strain data from ring tests, particularly when comparing data taken from different experimental programs. It was decided that the scatter in the ring test data in the PNNL database were too great to be used in model fitting. However, the ring test yield stress and ultimate tensile strength data were compared to the final models for yield stress and ultimate tensile strength and were found to fit as well as the axial and burst test data used to develop these models.

This report is divided into seven sections. Section 1 contains an introduction. Section 2 describes the Zircaloy mechanical models that have been developed. Section 3 shows model to data comparisons. Section 4 discusses the effects that specimen gage length and width have on the measured properties. Section 5 discusses the application of the mechanical property models to spent fuel cladding analyses. Section 6 provides conclusions and references are provided in Section 7.

\section{Zircaloy Mechanical Model}

The stress vs. strain behavior of Zircaloy is described by two different correlations, depending on the stress. Before yield, Hooke's law (Equation 1) is used to describe the elastic deformation of the Zircaloy.

$\sigma=\varepsilon \cdot E$

(Equation 1)

where:

$\sigma=$ stress

$\varepsilon=$ strain

$\mathrm{E}=$ elastic modulus 
After yield, the power law (Equation 2) is used to describe the plastic deformation of the Zircaloy.

$\sigma=K \cdot \varepsilon^{n}\left(\frac{\dot{\varepsilon}}{10^{-3}}\right)^{m}$

where:

$\mathrm{K}=$ strength coefficient

$\mathrm{n}=$ strain hardening exponent

$\mathrm{m}=$ strain rate exponent

$\dot{\varepsilon}=$ strain rate, $\mathrm{s}^{-1}$

The yield stress is given as the non-zero intersection of Equations 1 and 2. The intersection of these equations is given in Equation 3.

$\sigma_{y}=\left[\frac{K}{E^{n}}\left(\frac{\dot{\varepsilon}}{10^{-3}}\right)^{m}\right]^{\left(\frac{1}{1-n}\right)}$

(Equation 3)

The ultimate tensile strength can be approximated by the stress predicted by Equation 2, when the strain is the sum of the plastic strain at maximum load and the strain at yield, $\sigma_{\mathrm{y}} / \mathrm{E}$. The plastic strain at maximum load is typically referred to as uniform elongation (UE) by the fuel vendors. In this report the quantity describing the plastic strain at maximum load will be referred to as uniform elongation. A sample true stress vs. true strain curve can be seen in Figure 1. In this figure, the true stress strain behavior that is predicted by the model can be seen. The two parts, elastic and plastic, which make up this curve, as described above, can also be seen.

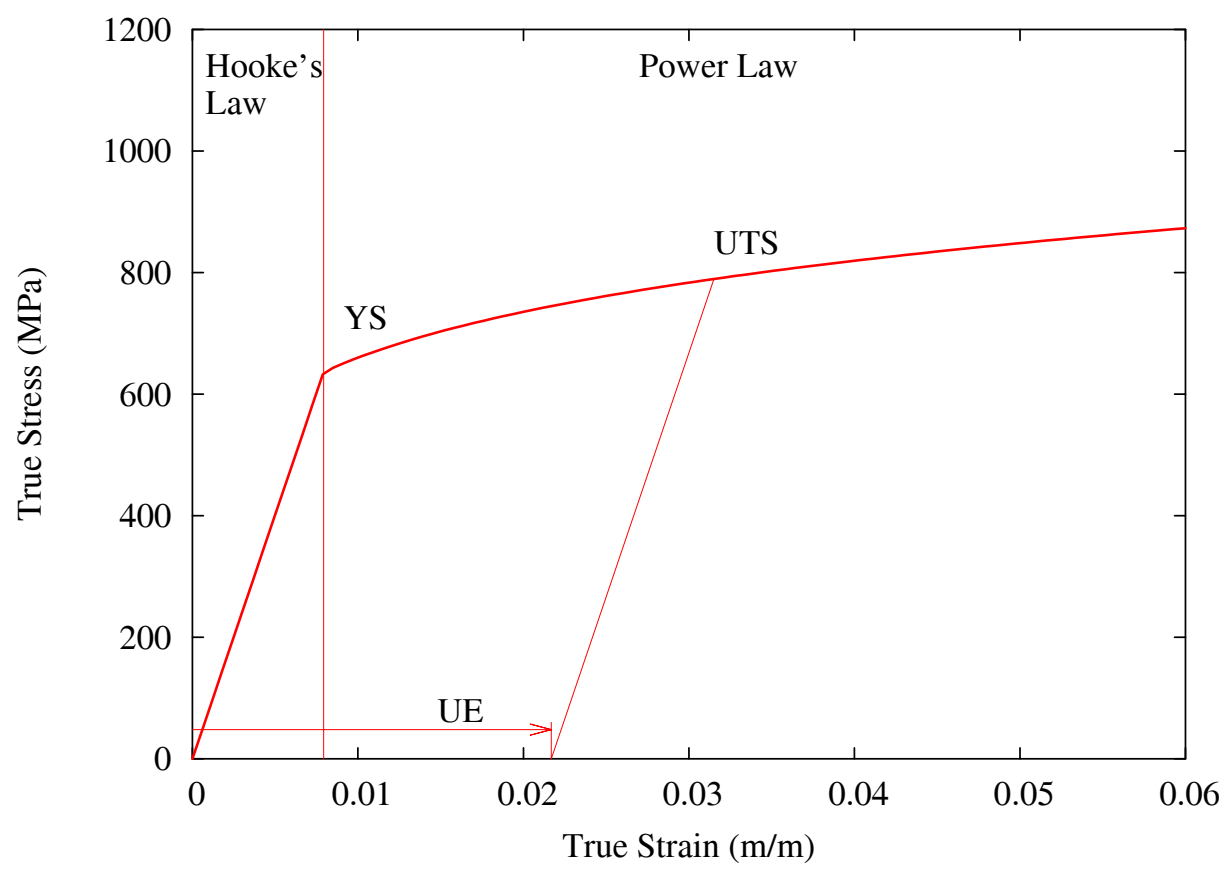

Figure 1: Sample true stress vs. true strain curve using new model. 
Empirical models for E, K, n, m, and UE were developed and are described in detail below.

It is noted that the stress and strain in this figure are true stress and strain and are calculated from load and displacement using the instantaneous value of cross sectional area and gage length, respectively. Engineering stress and strain differs from true stress and strain in that it is calculated from load and displacement using the initial value of cross sectional area and gage length, respectively. A plot of engineering stress vs. engineering strain would look similar to Figure 1 below the ultimate tensile strength. However, beyond this point the engineering stress would decrease because the crosssectional area is becoming smaller than its initial value.

\section{$\underline{2.1 \text { Elastic Modulus }}$}

The elastic modulus of Zircaloy that was used in this model is the same model that is given in MAPTRO- $11^{27}$. The description of this model is given below.

$$
\begin{array}{ll}
E=\frac{1.088 \times 10^{11}-5.475 \times 10^{7} \cdot T+K_{1}+K_{2}}{K_{3}} & \mathrm{~T} \leq 1090 \mathrm{~K} \\
E=(E(1255)-E(1090)) \frac{T-1090}{1255-1090}+E(1090) & 1090 \mathrm{~K}<\mathrm{T}<1255 \mathrm{~K} \\
E=9.21 \times 10^{10}-4.05 \times 10^{7} \cdot T & \mathrm{~T} \geq 1255 \mathrm{~K}
\end{array}
$$

where:

$\mathrm{E}=$ elastic modulus, $\mathrm{Pa}$

$\mathrm{T}=$ temperature, $\mathrm{K}$

$K_{1}=\left(6.61 \times 10^{11}+5.912 \times 10^{8} \cdot T\right) \Delta$

$\Delta=$ average oxygen concentration minus oxygen concentration of as-received cladding (kg oxygen $/ \mathrm{kg}$ Zircaloy)

$K_{2}=-2.6 \times 10^{10} \cdot C W$

$\mathrm{CW}=$ cold work, unitless ratio of areas (valid from 0 to 0.75 )

$K_{3}=0.88+0.12 \exp \left(-\Phi / 10^{25}\right)$

$\Phi=$ fast neutron fluence, $\mathrm{n} / \mathrm{m}^{2}(\mathrm{E}>1 \mathrm{MeV})$

\section{$\underline{2.2 \text { Strength Coefficient }}$}

The strength coefficient, $\mathrm{K}$, has been modified from MATPRO ${ }^{27}$ and is a function of temperature, fast neutron fluence, cold work, and alloy composition. The strength coefficient has not been found to be a function of hydrogen concentration. The fluence dependency, $K(\Phi)$, has been modified from MATPRO in order to better fit the high burnup data. The models for the strength coefficients of Zircaloy-2 and Zircaloy-4 are given below.

$$
K=K(T) \cdot(1+K(C W)+K(\Phi)) / K(Z r y)
$$


Where:

$\mathrm{K}=$ strength coefficient, $\mathrm{Pa}$

$$
\begin{aligned}
& K(T)=1.17628 \times 10^{9}+4.54859 \times 10^{5} T-3.28185 \times 10^{3} T^{2}+1.72752 \cdot T^{3} \quad \mathrm{~T}<750 \mathrm{~K} \\
& K(T)=2.522488 \times 10^{6} \exp \left(\frac{2.8500027 \times 10^{6}}{T^{2}}\right) \quad 750 \mathrm{~K}<\mathrm{T}<1090 \mathrm{~K} \\
& K(T)=1.841376039 \times 10^{8}-1.4345448 \times 10^{5} \mathrm{~T} \quad 1090 \mathrm{~K}<\mathrm{T}<1255 \mathrm{~K} \\
& K(T)=4.330 \times 10^{7}-6.685 \times 10^{4} T+3.7579 \times 10^{1} T^{2}-7.33 \times 10^{-3} T^{3} 1255 \mathrm{~K}<\mathrm{T}<2100 \mathrm{~K} \\
& K(C W)=0.546 \cdot C W \\
& K(\Phi)=\left(-0.1464+1.464 \times 10^{-25} \Phi\right) f(C W, T) \quad \Phi<0.1 \times 10^{25} \mathrm{n} / \mathrm{m}^{2} \\
& K(\Phi)=2.928 \times 10^{-26} \Phi \quad 0.1 \times 10^{25} \mathrm{n} / \mathrm{m}^{2}<\Phi<2 \times 10^{25} \mathrm{n} / \mathrm{m}^{2} \\
& K(\Phi)=0.53236+2.6618 \times 10^{-27} \Phi \quad 2 \times 10^{25} \mathrm{n} / \mathrm{m}^{2}<\Phi<12 \times 10^{25} \mathrm{n} / \mathrm{m}^{2} \\
& f(C W, T)=2.25 \exp (-20 \cdot C W) \cdot \min \left[1, \exp \left(\frac{T-550}{10}\right)\right]+1
\end{aligned}
$$

\subsection{Strain Hardening Exponent}

The strain hardening exponent, $\mathrm{n}$, has been modified from MATPRO ${ }^{27}$ in order to better fit the high burnup data and is a function of temperature, fast neutron fluence, and alloy composition. The strain hardening exponent has not been found to be a function of hydrogen concentration. The models for the strain hardening exponents of Zircaloy-2 and Zircaloy-4 are given below.

$$
n=n(T) \cdot n(\Phi) / n(Z r y)
$$

where:

$n=$ strain hardening exponent

$$
\begin{array}{lc}
n(T)=0.11405 & \mathrm{~T}<419.4 \mathrm{~K} \\
n(T)=-9.490 \times 10^{-2}+1.165 \times 10^{-3} T-1.992 \times 10^{-6} T^{2}+9.588 \times 10^{-10} T^{3} & 419.4 \mathrm{~K}<\mathrm{T}<1099.0772 \mathrm{~K} \\
n(T)=-0.22655119+2.5 \times 10^{-4} T & 1099.0772 \mathrm{~K}<\mathrm{T}<1600 \mathrm{~K} \\
n(T)=0.17344880 & \mathrm{~T}>1600 \mathrm{~K} \\
n(\Phi)=1.321+0.48 \times 10^{-25} \Phi & \Phi<0.1 \times 10^{25} \mathrm{n} / \mathrm{m}^{2} \\
n(\Phi)=1.369+0.096 \times 10^{-25} \Phi & 0.1 \times 10^{25} \mathrm{n} / \mathrm{m}^{2}<\Phi<2 \times 10^{25} \mathrm{n} / \mathrm{m}^{2} \\
n(\Phi)=1.5435+0.008727 \times 10^{-25} \Phi & 2 \times 10^{25} \mathrm{n} / \mathrm{m}^{2}<\Phi<7.5 \times 10^{25} \mathrm{n} / \mathrm{m}^{2} \\
n(\Phi)=1.608953 & \Phi>7.5 \times 10^{25} \mathrm{n} / \mathrm{m}^{2} \\
n(\text { Zry })=1 \text { for Zircaloy-4 } & \\
n(\text { Zry })=1.6 \text { for Zircaloy-2 } & \\
\mathrm{T}=\text { temperature, K } &
\end{array}
$$


$\Phi=$ fast neutron fluence, $\mathrm{n} / \mathrm{m}^{2}(\mathrm{E}>1 \mathrm{MeV})$

\subsection{Strain Rate Exponent}

The strain rate exponent, $\mathrm{m}$, has been modified from MATPRO ${ }^{27}$ to better fit the high burnup data and is given by a function of temperature only as described in the equation below.

$m=0.015$ $\mathrm{T}<750 \mathrm{~K}$

$m=7.458 \times 10^{-4} T-0.544338$ $750 \mathrm{~K}<\mathrm{T}<800 \mathrm{~K}$

$m=3.24124 \times 10^{-4} T-0.20701$ $\mathrm{T}>800 \mathrm{~K}$

where:

$m=$ strain rate exponent

$\mathrm{T}=$ temperature, $\mathrm{K}$

The impact of the strain rate exponent on yield stress is to increase the yield strength with increasing strain rate, but the effect is not large. For example, increasing the strain rate from $1 \times 10^{-4} / \mathrm{s}$ to $1.0 / \mathrm{s}$ will increase the yield strength by about $15 \%$.

\section{$\underline{2.5 \text { Uniform Elongation }}$}

The model for uniform plastic elongation for irradiated Zircaloy is given below and has been modified from that recommended in $\mathrm{MATPRO}^{27}$ to better fit the high burnup data. This model can be used for un-irradiated Zircaloy, but there is considerable scatter in the unirradiated data. It is noted that this model is based on irradiated Zircaloy cladding containing circumferential hydrides. This model applies only to cladding with circumferential hydrides and does not apply to cladding with radial hydrides or significant hydride blisters or spalling.

$U E=\min \left(U E_{0}, U E_{\text {Hex }}\right)$

where:

$\mathrm{UE}=$ uniform plastic elongation, $\%$

$\mathrm{UE}_{0}=2.2 \%$

$U E_{\text {Hex }}=A \cdot H_{e x}^{-p} \quad \mathrm{H}_{\mathrm{ex}}>0$

$U E_{\text {Hex }}=U E_{0}$

$\mathrm{H}_{\mathrm{ex}}=0$

$A=1211 \exp (-0.00927 \cdot T)$

$\mathrm{T}<700 \mathrm{~K}$

$A=1.840803$

$\mathrm{T}>700 \mathrm{~K}$

$p=1.355231-0.001783 \cdot T$

$\mathrm{T}<700 \mathrm{~K}$

$p=0.107131$

$\mathrm{T}>700 \mathrm{~K}$

$H_{e x}=\max \left(0, H_{\text {Tot }}-H_{\text {Sol }}\right)$

$H_{\text {Sol }}=1.2 \times 10^{5} \exp \left(\frac{-8550}{1.985887 \cdot T}\right)$

$\mathrm{H}_{\text {Tot }}=$ total hydrogen in cladding, ppm

$\mathrm{T}=$ temperature, $\mathrm{K}$ 
The excess hydrogen calculated above is found using the steady state hydrogen solubility. In the case of fast transients, the hydrogen takes a finite time to go into solution. In order to model this dissolution time, the hydrogen dissolution and precipitation rates must be modeled as discussed in a separate paper ${ }^{28}$. The maximum predicted strain allowed by this model is $2.2 \%$ as fixed by the term, $\mathrm{UE}_{0}$. This term has been selected as an average value of uniform elongation from specimens with no excess hydrogen.

The model for uniform elongation is not a function of fast neutron fluence. However, as the data that were used in model development are taken from in-reactor cladding specimens, there is somewhat of a correlation between hydrogen concentration and fast neutron fluence. Presented in Figure 2 is the hydrogen concentration data as a function of fast neutron fluence for the data in the PNNL database. It can be seen that as fluence increases, hydrogen content tends to increase as well. The best fit to uniform elongation data was found as a function of hydrogen content rather than fast neutron fluence. It should be noted that not all data with high fluence will have high hydrogen and viceversa because some mechanical specimens are artificially hydrogen charged without being irradiated and others may be from a test reactor with low temperatures and, therefore, low corrosion and hydrogen.

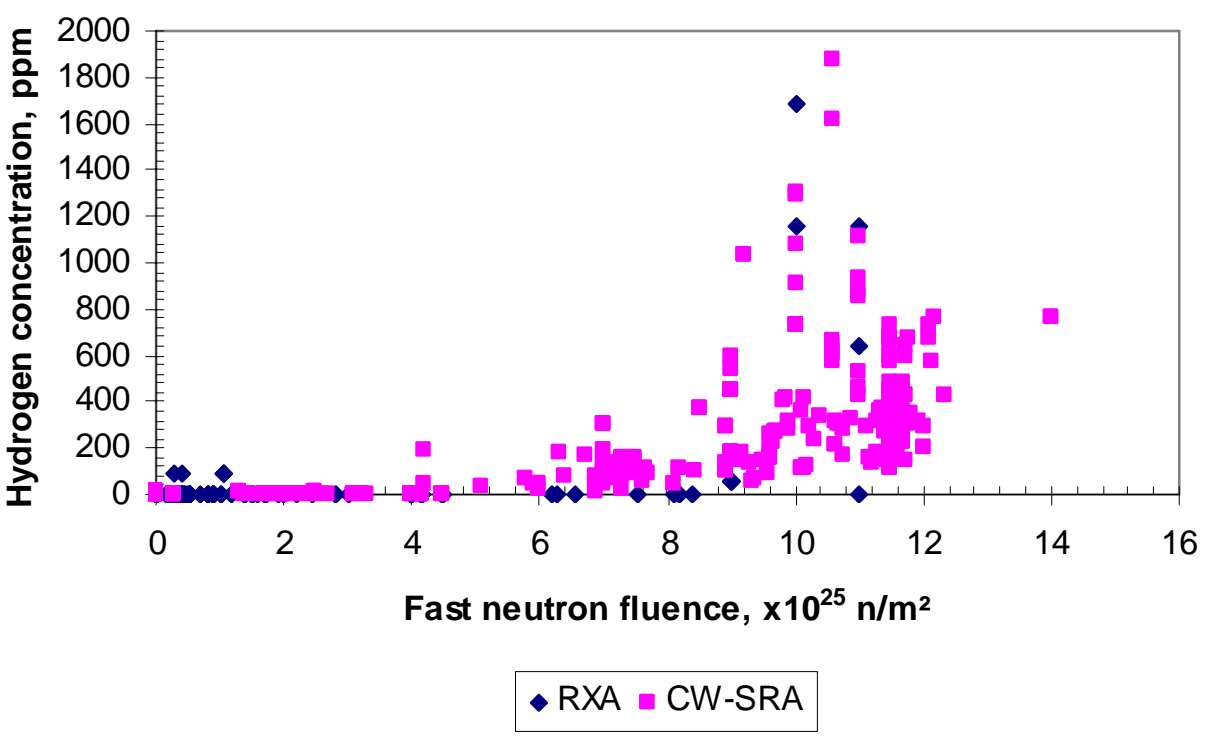

Figure 2. Hydrogen concentration vs. fast neutron fluence for the data in the PNNL database. $(293 \mathrm{~K} \leq \mathrm{T} \leq 755 \mathrm{~K})$.

\section{Data comparisons}

Provided in this section are comparisons of the new stress/strain correlations to the available data. The modified yield stress from the burst tests and the measured yield stress from the axial tension tests from the PNNL database and the measured yield stress from the PROMETRA plotted data are compared to the model predictions. The adjusted (adjusted to uniaxial stress) ultimate tensile strength data from the burst tests and the measured ultimate tensile strength from the uniaxial tension tests (from the PNNL database) are compared to the model predictions. The measured uniform elongations 
from the burst tests and uniaxial tension tests (from the PNNL database) from irradiated samples are compared to the model predictions. Several measured stress vs. strain curves from the PNNL database are compared to the model predictions up to the end of the uniform elongation. Finally the measured yield stress and ultimate tensile strength from the ring tests (from the PNNL database) are compared with the model predictions.

\section{$\underline{3.1 \text { Yield Stress }}$}

Figure 3 shows a plot of predicted yield stress vs. measured yield stress for burst tests and axial tension tests from Zircaloy- 2 and Zircaloy- 4 in the PNNL database. It can be seen from this figure that the model predicts the data quite well. Generally the upper and lower bound in such yield stress data is $\pm 140 \mathrm{MPa}$, while the model standard error is 65 $\mathrm{MPa}$. When comparing the irradiated ANL axial tensile data to other data in the database taken under identical conditions, the ANL data were found to be lower than the other data by up to $20 \%$. A possible reason for this difference is gage geometry. This will be discussed in greater detail in Section 4. Therefore these data are excluded from the model development and error calculations. There is one datum point that is significantly overpredicted in Figure 3 and the following figures. This overprediction is from a fuel rod cladding sample at high burnup that had spalled oxide resulting in significant hydride blister and severe embrittlement. This resulted in failure $40 \%$ below the yield strength of similar high burnup cladding samples without hydride blisters.

Figures 4, 5, 6, and 7 show the predicted minus measured values for the PNNL database as a function of fluence, cold work, strain rate, and temperature, respectively. It can be seen from these figures that there is no apparent bias as a function of cold work, fluence, strain rate, or temperature.

Figure 7 shows the predicted minus measured yield stress as a function of temperature. It can be seen from this figure that there is considerable data at room temperature (300K) and between $560 \mathrm{~K}$ and $700 \mathrm{~K}$, but very little data between $300 \mathrm{~K}$ and $560 \mathrm{~K}$. The model predicts the limited data between $300 \mathrm{~K}$ and $560 \mathrm{~K}$ well, but more data would increase the reliability of the interpolation in this temperature range.

Figure 8 shows the predicted minus measured yield stress for the PNNL database as a function of excess hydrogen. PNNL has not observed any change in yield stress as a function of hydrogen concentration. However, an increase in fluence generally results in an increase in hydrogen for some data sets that makes it difficult to separate the effects of these two parameters. If hydrogen were to have an effect it would be expected to increase the yield stress but Figure 8 does not show significant model bias for yield stress with increasing hydrogen. Yield stress is apparently over predicted by a small amount on average when excess hydrogen exceeds $600 \mathrm{ppm}$ as shown in Figure 8. Examination of these data shows that the uniform elongation strains were very low for these cladding samples suggesting that the decrease in yield stress is due to embrittlement and not due to elastic-plastic deformation and therefore, can not be predicted well with these equations. This is further illustrated by significantly overpredicting yield stress for the cladding sample that has significant oxide spallation, hydride blisters, and severe embrittlement. 


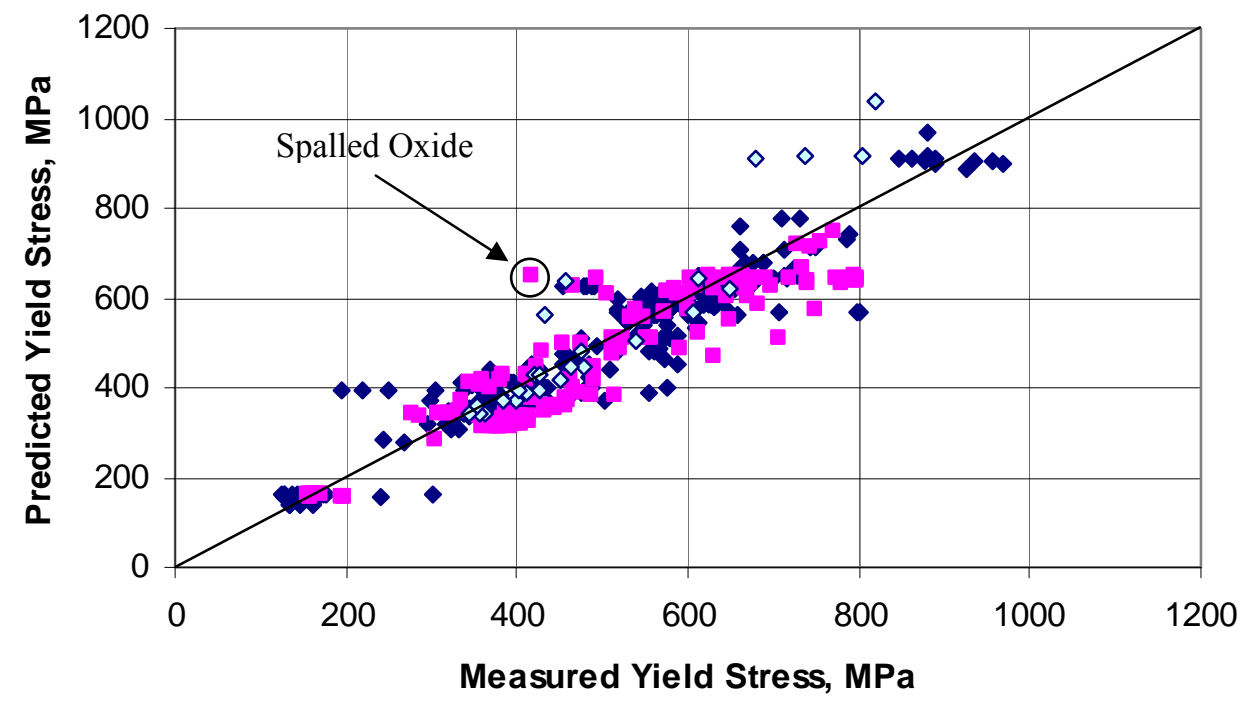

- Axial Tests - Burst Tests $\diamond$ ANL Axial Tests

Figure 3: Predicted vs. measured yield stress from the PNNL database $\left.(293 \mathrm{~K} \leq \mathrm{T} \leq 755 \mathrm{~K}), 0 \leq \Phi \leq 14 \times 10^{25} \mathrm{n} / \mathrm{m}^{2}, 0 \leq \mathrm{H}_{\mathrm{ex}} \leq 850 \mathrm{ppm}\right)$.

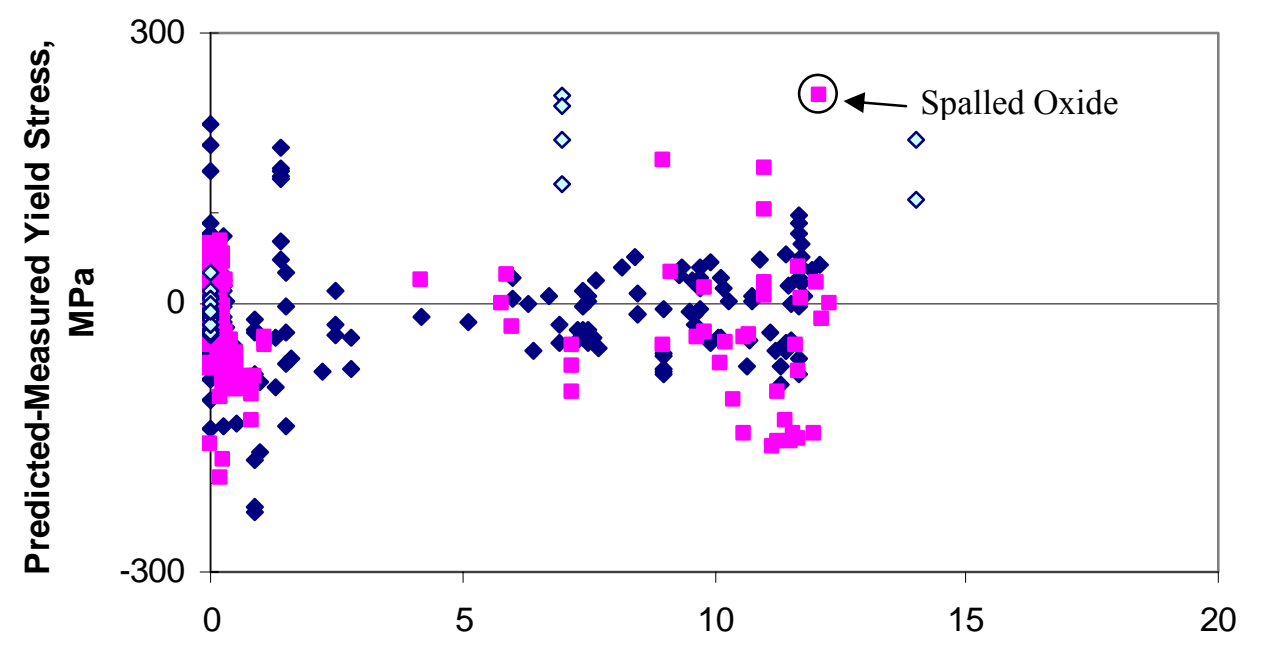

Fluence, $n / m^{2 *} 1 e-25$

- Axial Tests $\bullet$ Burst Tests $\diamond$ ANL Axial Tests

Figure 4: Predicted minus measured yield stress from the PNNL database as a function of fluence $\left(293 \mathrm{~K} \leq \mathrm{T} \leq 755 \mathrm{~K}\right.$ and $\left.0 \leq \mathrm{H}_{\mathrm{ex}} \leq 850 \mathrm{ppm}\right)$. 


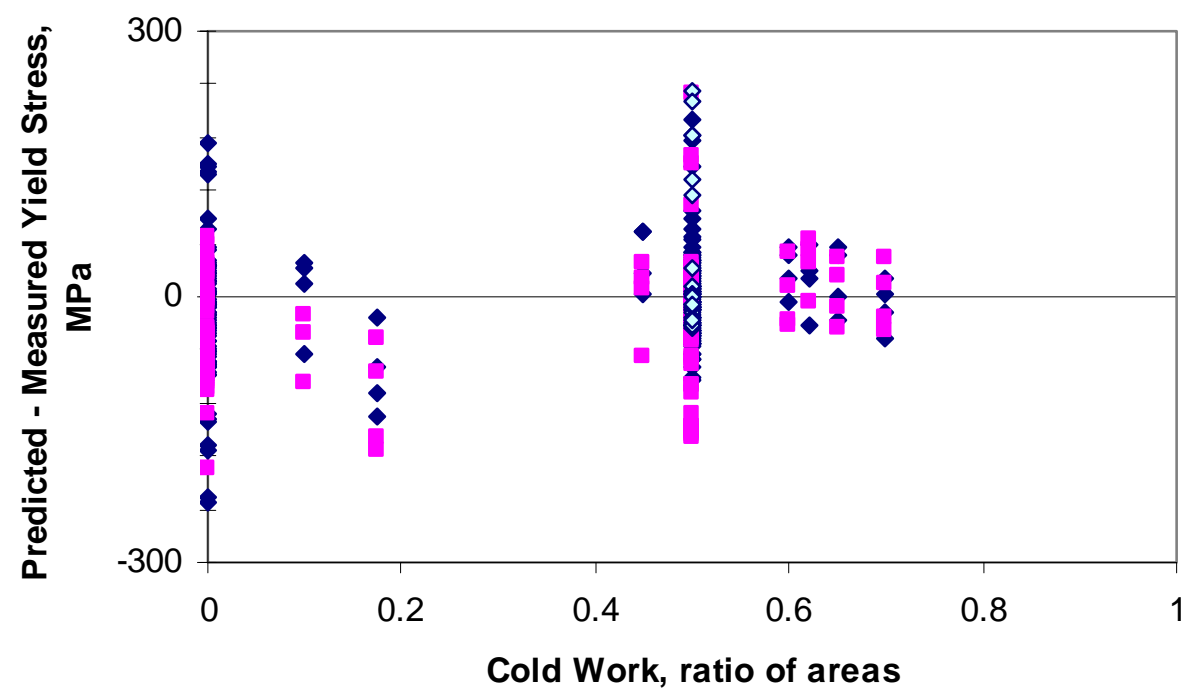

- Axial Tests - Burst Tests $\diamond$ ANL Axial Tests

Figure 5: Predicted minus measured yield stress from the PNNL database as a function of cold work $\left(293 \mathrm{~K} \leq \mathrm{T} \leq 755 \mathrm{~K}, 0 \leq \Phi \leq 14 \times 10^{25} \mathrm{n} / \mathrm{m}^{2}, 0 \leq \mathrm{H}_{\mathrm{ex}} \leq 850 \mathrm{ppm}\right)$.

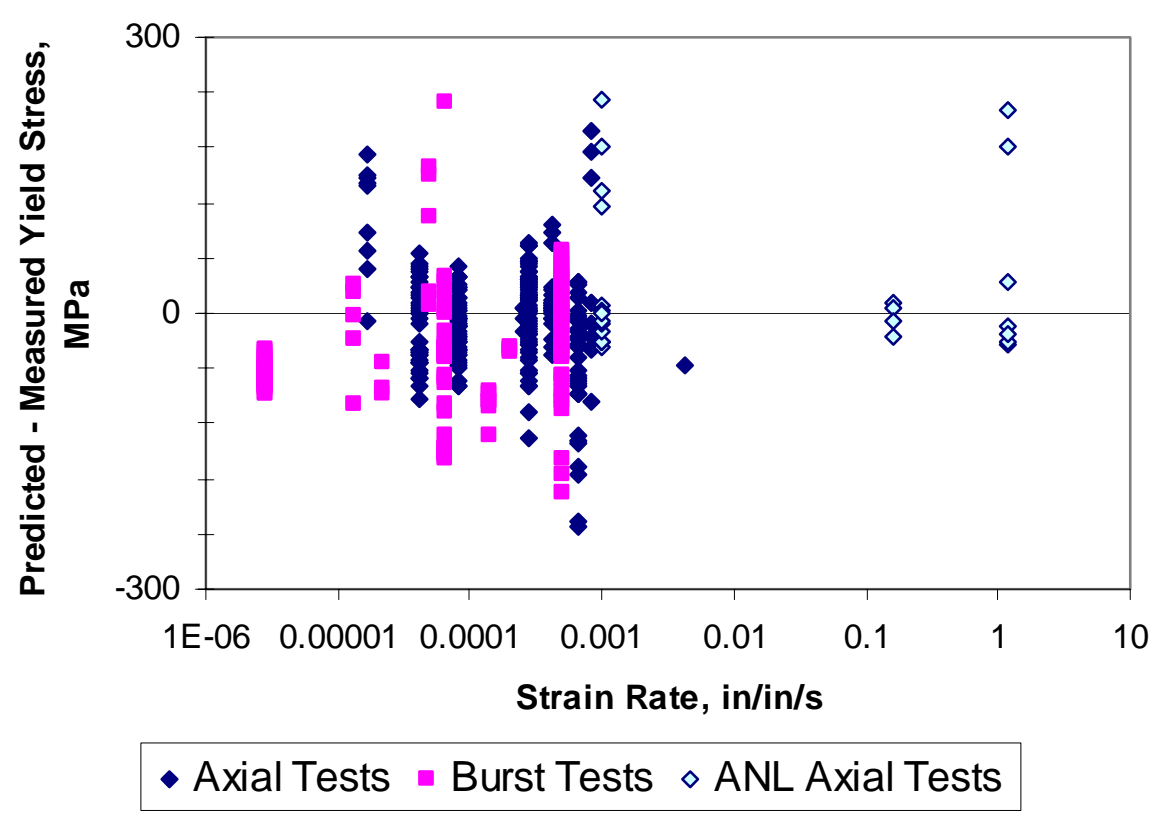

Figure 6: Predicted minus measured yield stress from the PNNL database as a function of strain rate $\left(293 \mathrm{~K} \leq \mathrm{T} \leq 755 \mathrm{~K}, 0 \leq \Phi \leq 14 \times 10^{25} \mathrm{n} / \mathrm{m}^{2}, 0 \leq \mathrm{H}_{\mathrm{ex}} \leq 850 \mathrm{ppm}\right)$. 


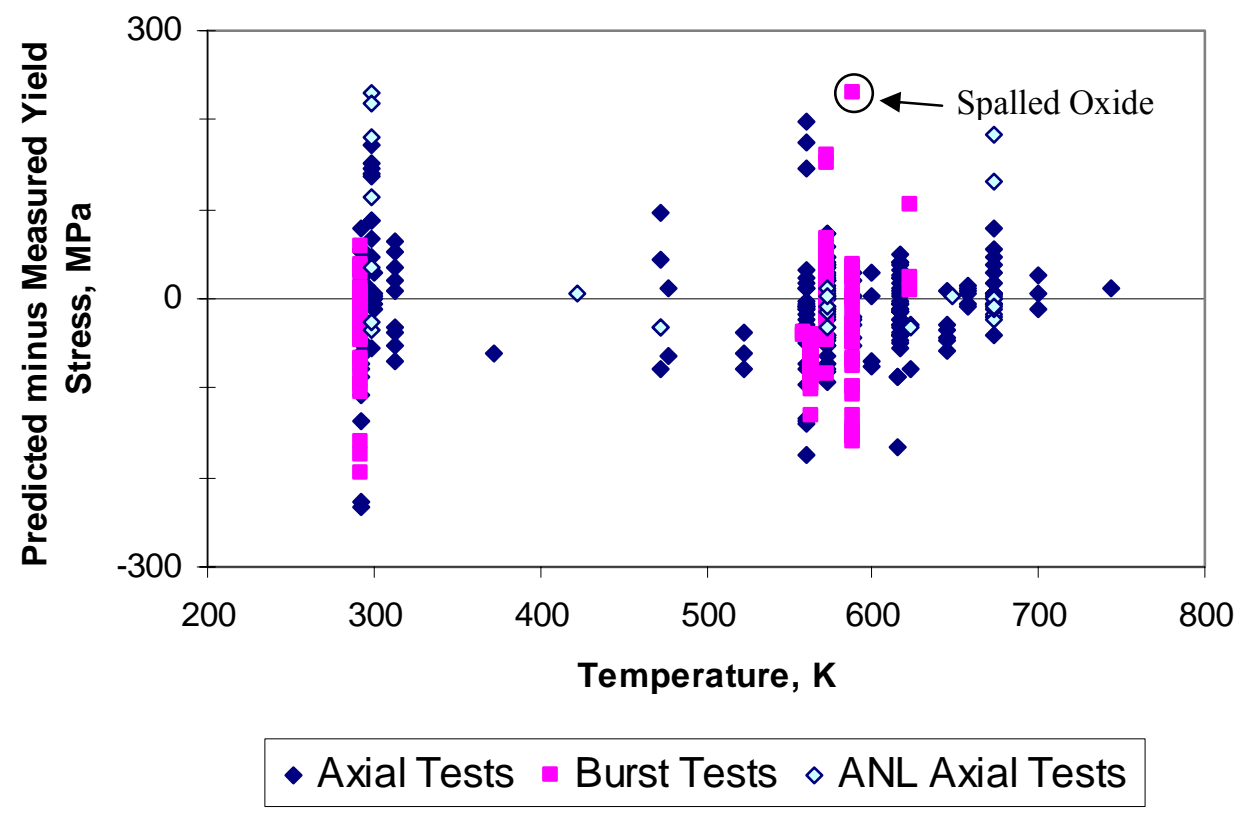

Figure 7: Predicted minus measured yield stress from the PNNL database as a function of temperature $\left(0 \leq \Phi \leq 14 \times 10^{25} \mathrm{n} / \mathrm{m}^{2}\right.$ and $\left.0 \leq H_{\mathrm{ex}} \leq 850 \mathrm{ppm}\right)$.

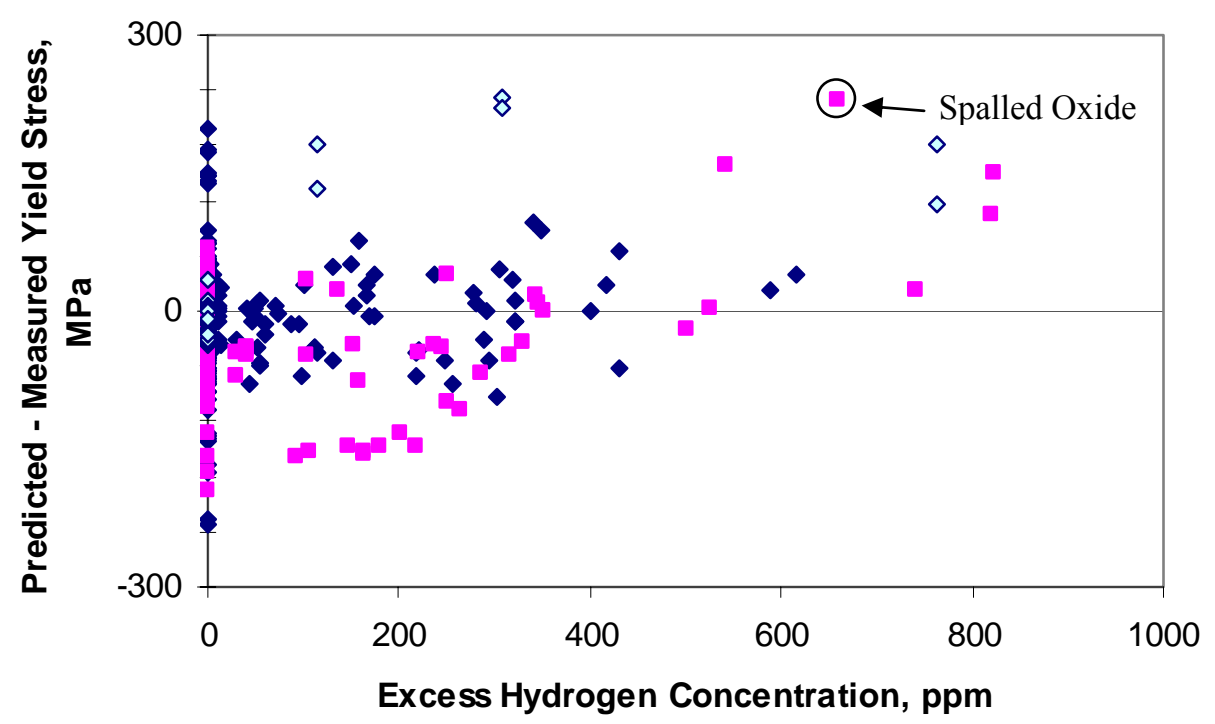

\section{- Axial Tests - Burst Tests $\diamond$ ANL Axial Tests}

Figure 8: Predicted minus measured yield stress from the PNNL database as a function of excess hydrogen $\left(293 \mathrm{~K} \leq \mathrm{T} \leq 755 \mathrm{~K}, 0 \leq \Phi \leq 14 \times 10^{25} \mathrm{n} / \mathrm{m}^{2}\right)$.

Figure 9 shows the PROMETRA data ${ }^{25}$ from ring (hoop) and axial tensile tests performed by CEA in France, and the new model predictions for several different strain rates. The actual cold work and fluence values for the samples in the PROMETRA database were not given so a value of $50 \%$ was assumed for the cold work and a value of $8 \times 10^{25} \mathrm{n} / \mathrm{m}^{2}$ was assumed for fluence. The fluence for the data shown in Figure 9 ranges 
from $6 \times 10^{25}$ to $12 \times 10^{25} \mathrm{n} / \mathrm{m}^{2}$ as reported ${ }^{25}$. From this figure it can be seen that the model predicts the data well as a function of temperature and strain rate.

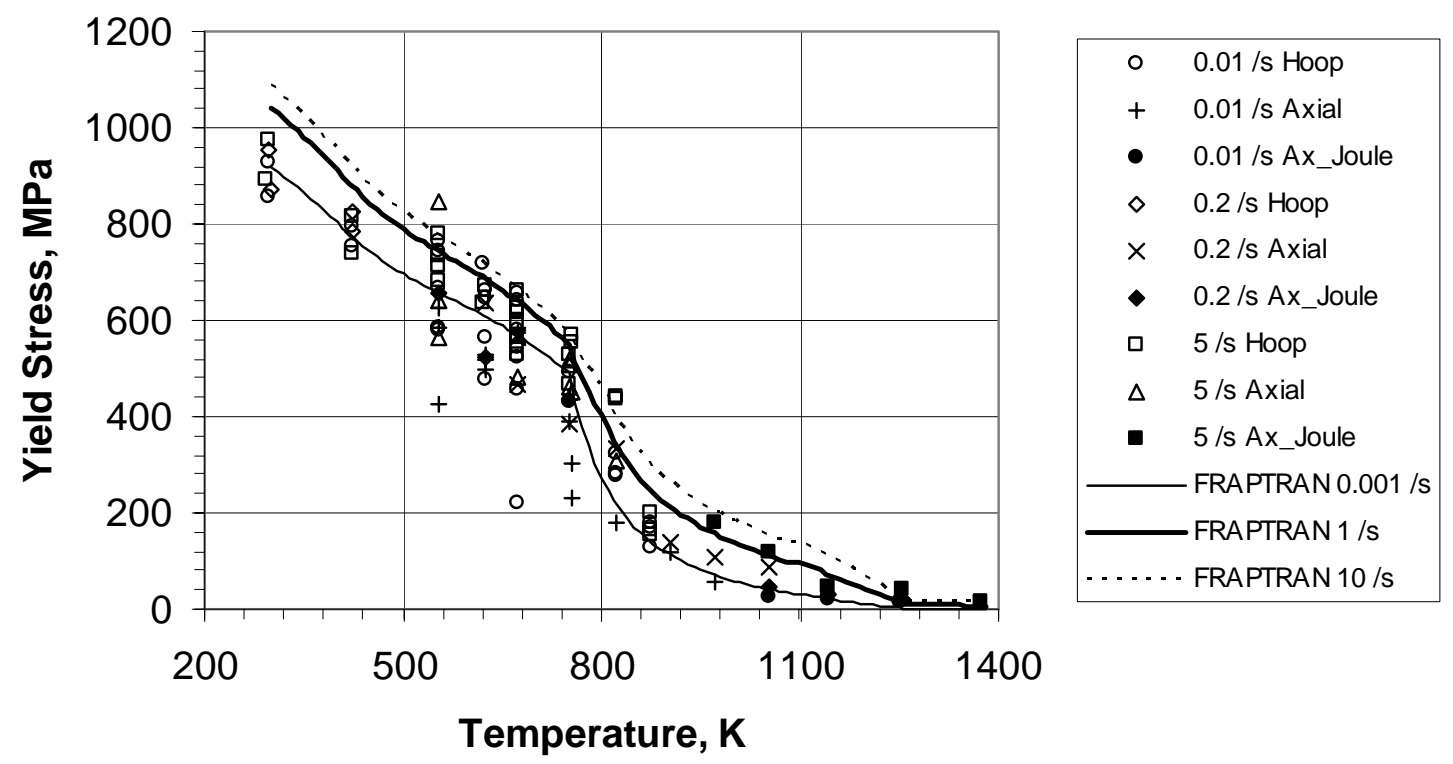

Figure 9: Predicted and measured yield stress from the PROMETRA database as a function of temperature for SRA Zircaloy-4.

\section{$\underline{3.2 \text { Ultimate Tensile Strength }}$}

Figure 10 shows a plot of predicted ultimate tensile strength vs. measured ultimate tensile strength for burst tests and axial tension tests from the PNNL database. It can be seen from this figure that the model predicts the data quite well. Generally the upper and lower bound in such ultimate tensile strength data is $\pm 140 \mathrm{MPa}$, while the model standard error is $66 \mathrm{MPa}$. It is expected that there will be greater uncertainty in the predictions of ultimate tensile strength than yield strength, because the calculation of ultimate tensile strength is based on both the calculation of yield stress and the calculation of uniform elongation. When comparing the irradiated ANL axial tensile data to other data in the database taken under identical conditions, the ANL data were found to be lower than the other data by up to $20 \%$ for irradiated cladding. A possible reason for this difference is gage geometry. This will be discussed in greater detail in Section 4. Therefore these data are excluded from the model development and error calculations. Also note that there are several high burnup cladding samples that are significantly over-predicted in Figures 10, $11,12,13,14$, and 15. These samples came from rods with spalled oxide with severe hydride blisters resulting in severe embrittlement. As seen in Figure 15 the samples that are over-predicted have high excess hydrogen concentration. All but one of these samples did not have a measured yield stress value due to failure occurring before the cladding yielded. 


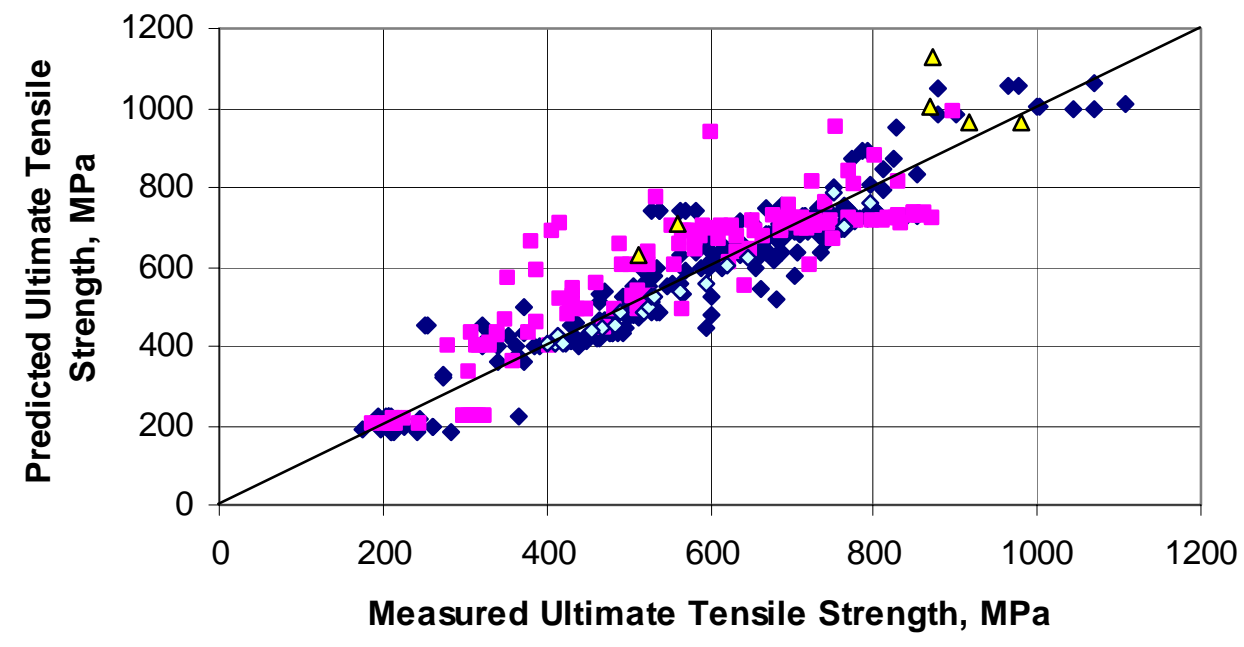

- Axial Tests - Burst Tests

$\diamond$ ANL Axial Tests (unirradiated) $\triangle$ ANL Axial Tests (irradiated)

Figure 10: Predicted vs. measured ultimate tensile strength from the PNNL database $\left(293 \mathrm{~K} \leq \mathrm{T} \leq 755 \mathrm{~K}, 0 \leq \Phi \leq 14 \times 10^{25} \mathrm{n} / \mathrm{m}^{2}, 0 \leq \mathrm{H}_{\mathrm{ex}} \leq 850 \mathrm{ppm}\right)$.

Figures 11, 12, 13, 14, and 15 show the predicted minus measured values for the PNNL database as a function of fluence, cold work, strain rate, temperature, and hydrogen concentration, respectively. It can be seen from these figures that there is no apparent bias as a function of fluence, cold work, strain rate, or temperature. There appears to be a small over prediction in ultimate tensile strength when excess hydrogen exceeds $600 \mathrm{ppm}$ (Figure 15) that may be due to the cladding embrittlement as discussed in Section 3.1 for yield stress. 


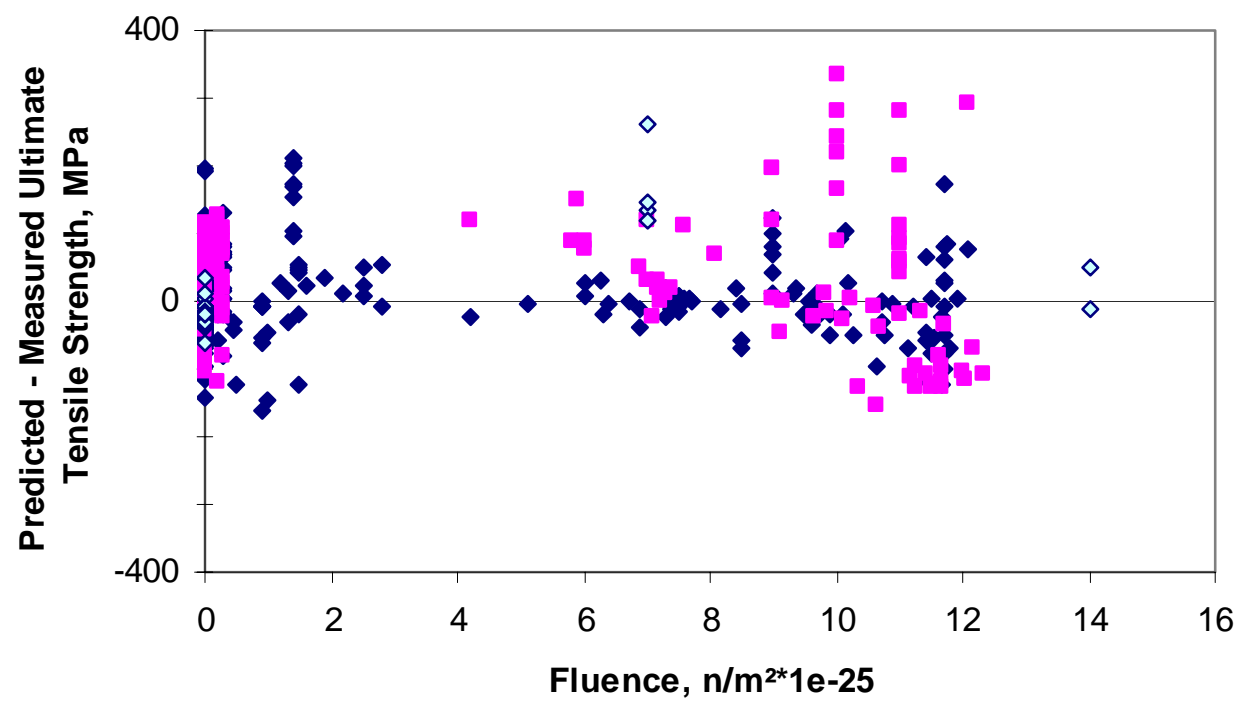

- Axial Tests - Burst Tests $\diamond$ ANL Axial Tests

Figure 11: Predicted minus measured ultimate tensile strength from the PNNL database as a function of fluence $\left(293 \mathrm{~K} \leq \mathrm{T} \leq 755 \mathrm{~K}\right.$ and $\left.0 \leq \mathrm{H}_{\mathrm{ex}} \leq 850 \mathrm{ppm}\right)$.

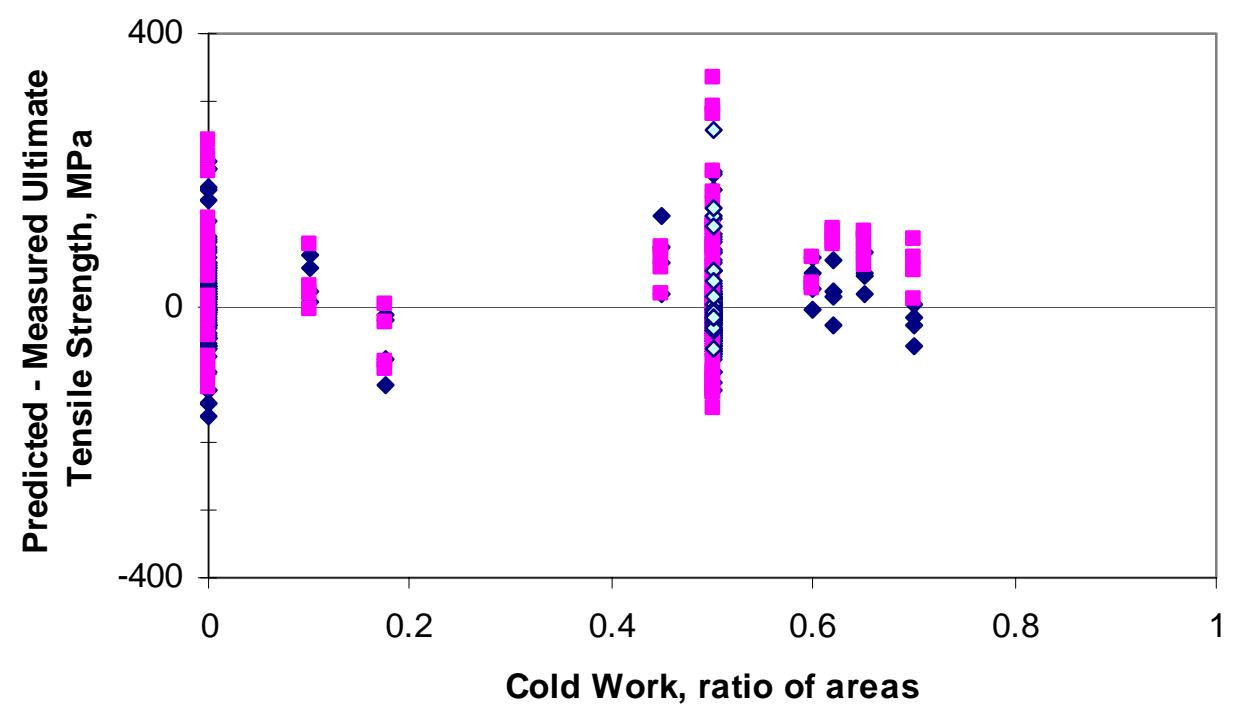

- Axial Tests - Burst Tests $\diamond$ ANL Axial Tests

Figure 12: Predicted minus measured ultimate tensile strength from the PNNL database as a function of cold work $\left(293 \mathrm{~K} \leq \mathrm{T} \leq 755 \mathrm{~K}, 0 \leq \Phi \leq 14 \times 10^{25} \mathrm{n} / \mathrm{m}^{2}, 0 \leq \mathrm{H}_{\mathrm{ex}} \leq 850 \mathrm{ppm}\right)$. 


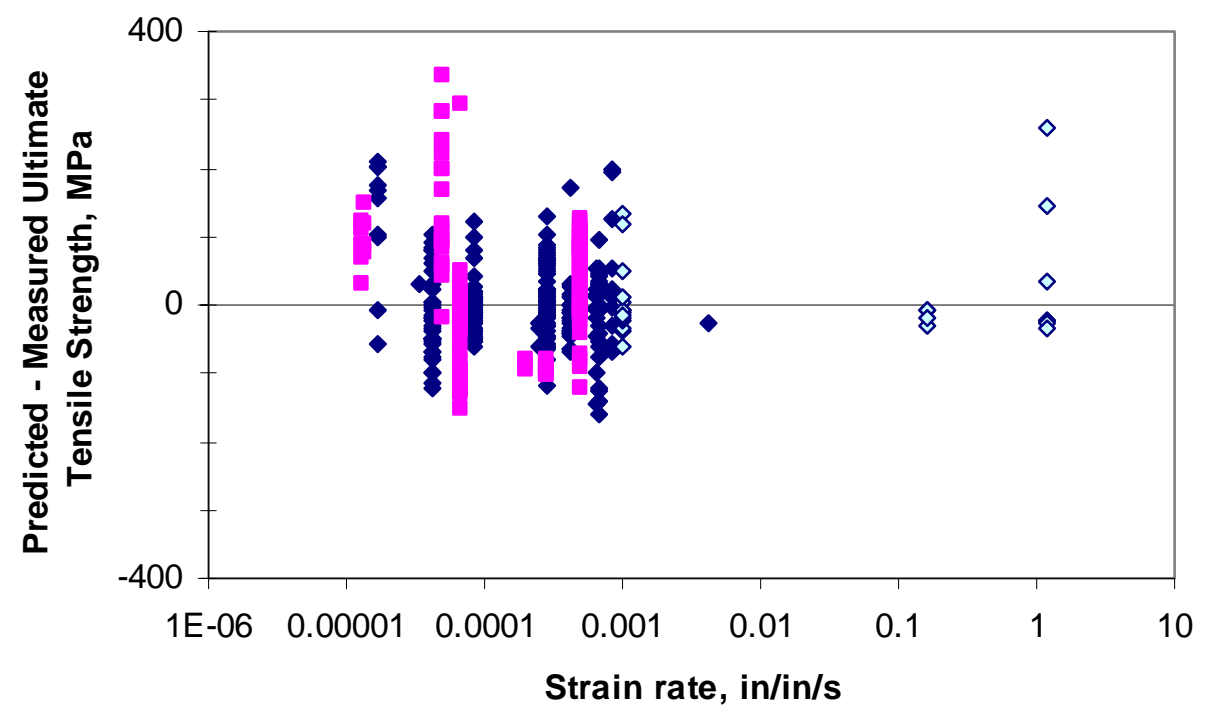

- Axial Tests - Burst Tests $\diamond$ ANL Axial Tests

Figure 13: Predicted minus measured ultimate tensile strength from the PNNL database as a function of strain rate $\left(293 \mathrm{~K} \leq \mathrm{T} \leq 755 \mathrm{~K}, 0 \leq \Phi \leq 14 \times 10^{25} \mathrm{n} / \mathrm{m}^{2}, 0 \leq \mathrm{H}_{\mathrm{ex}} \leq 850 \mathrm{ppm}\right)$.

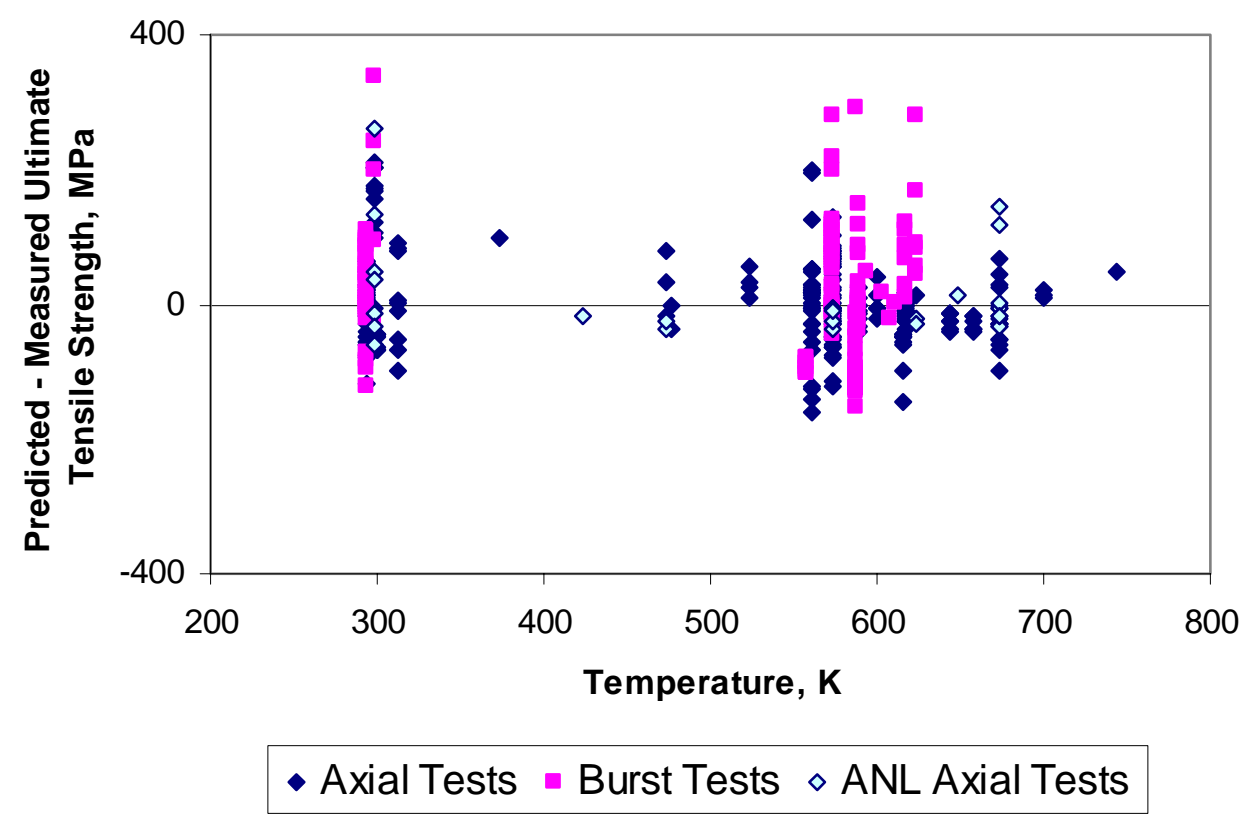

Figure 14: Predicted minus measured ultimate tensile strength from the PNNL database as a function of temperature $\left(0 \leq \Phi \leq 14 \times 10^{25} \mathrm{n} / \mathrm{m}^{2}\right.$ and $\left.0 \leq H_{\mathrm{ex}} \leq 850 \mathrm{ppm}\right)$. 


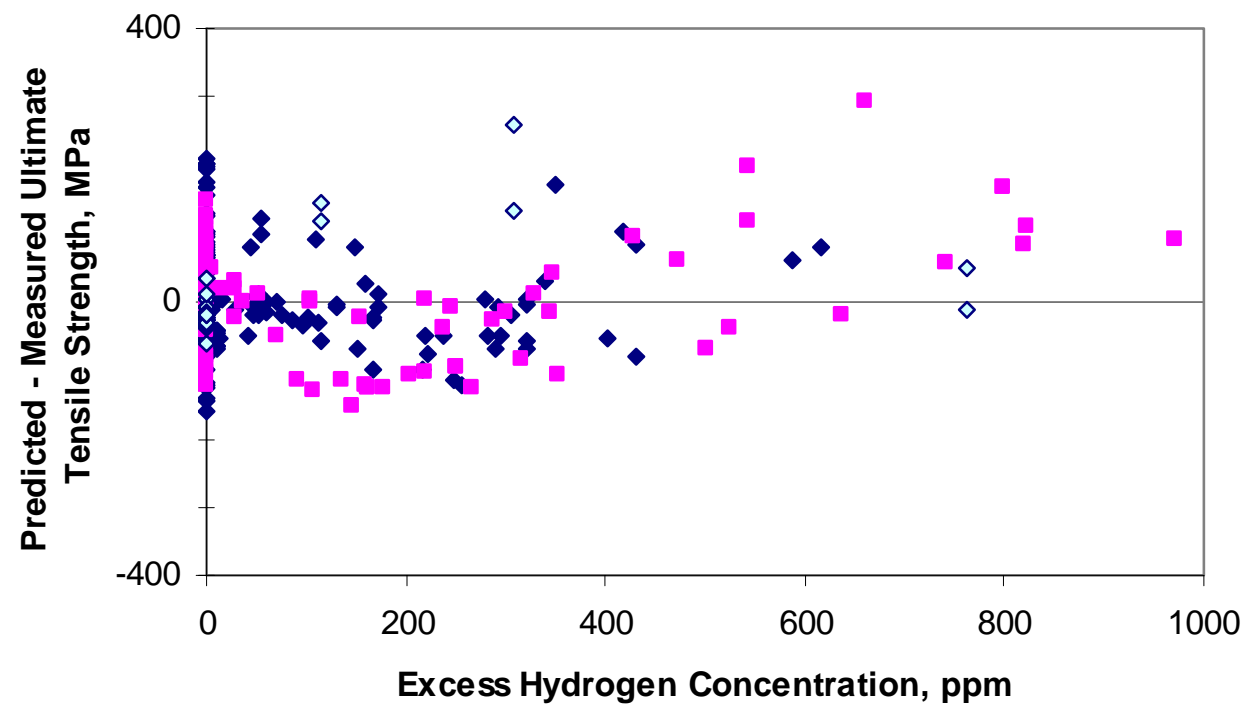

- Axial Tests - Burst Tests $\diamond$ ANL Axial Tests

Figure 15: Predicted minus measured ultimate tensile strength from the PNNL database as a function of excess hydrogen concentration $\left(293 \mathrm{~K} \leq \mathrm{T} \leq 755 \mathrm{~K}\right.$ and $\left.0 \leq \Phi \leq 14 \times 10^{25} \mathrm{n} / \mathrm{m}^{2}\right)$.

\subsection{Uniform elongation}

The predicted vs. measured uniform elongation are shown in Figure 16 for all of the irradiated data in the PNNL database. It can be seen from this figure that there exists a greater degree of scatter in these data than in the YS and UTS data. Most of the scatter at $2.2 \%$ predicted uniform elongation comes from irradiated cladding with very little total hydrogen concentration. The data from samples with little excess hydrogen has a range of $0-5 \%$, but as discussed in Section 2.5, an average value of $2.2 \%$ was selected as the model upper limit. The predicted minus measured values of uniform elongation from the irradiated samples in the PNNL database are shown in Figures 17 and 18 as a function of excess hydrogen and temperature, respectively. Excess hydrogen, $\mathbf{H}_{\mathbf{e x}}$, is defined as the hydrogen content above the solubility limit which is not dissolved in the matrix, i.e. excess hydrogen equals total hydrogen minus hydrogen dissolved in the matrix. It can be seen from these figures that the new model predicts the uniform elongation to within $\pm 1 \%$. The standard error is $0.9 \%$ strain at excess hydrogen less than $500 \mathrm{ppm}$. Figure 17 also demonstrates that the most scatter is seen in the uniform elongation when there is little or no excess hydrogen. When comparing the irradiated ANL axial tensile data to other data in the database taken under identical conditions, the ANL data were found to be significantly higher than the other data. A possible reason for this difference 
is gage geometry. This will be discussed in greater detail in Section 4 .

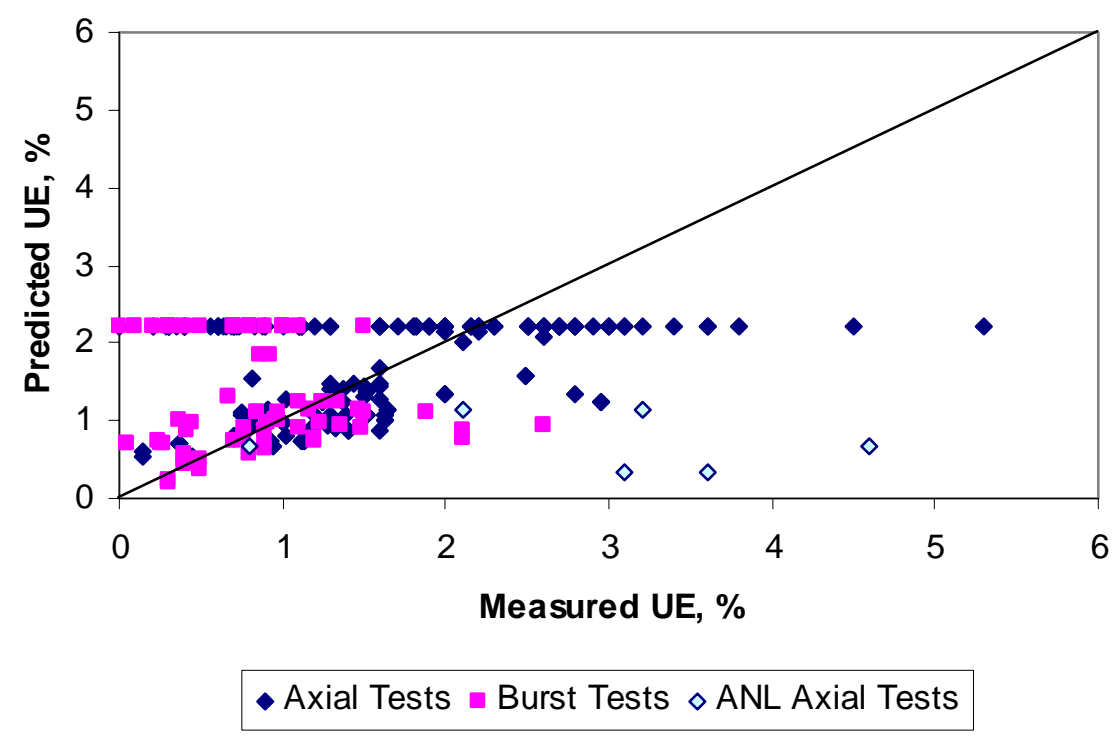

Figure 16: Predicted minus measured uniform elongation from irradiated samples from the PNNL database $\left(293 \mathrm{~K} \leq \mathrm{T} \leq 755 \mathrm{~K}, 0<\Phi \leq 14 \times 10^{25} \mathrm{n} / \mathrm{m}^{2}, 0 \leq \mathrm{H}_{\text {ex }} \leq 1630 \mathrm{ppm}\right)$. Note that the large scatter at $2.2 \%$ elongation is primarily from irradiated samples with very little total hydrogen and, therefore, essentially zero excess hydrogen $\left(10 \mathrm{ppm} \leq \mathrm{H}_{\mathrm{ex}}\right)$.

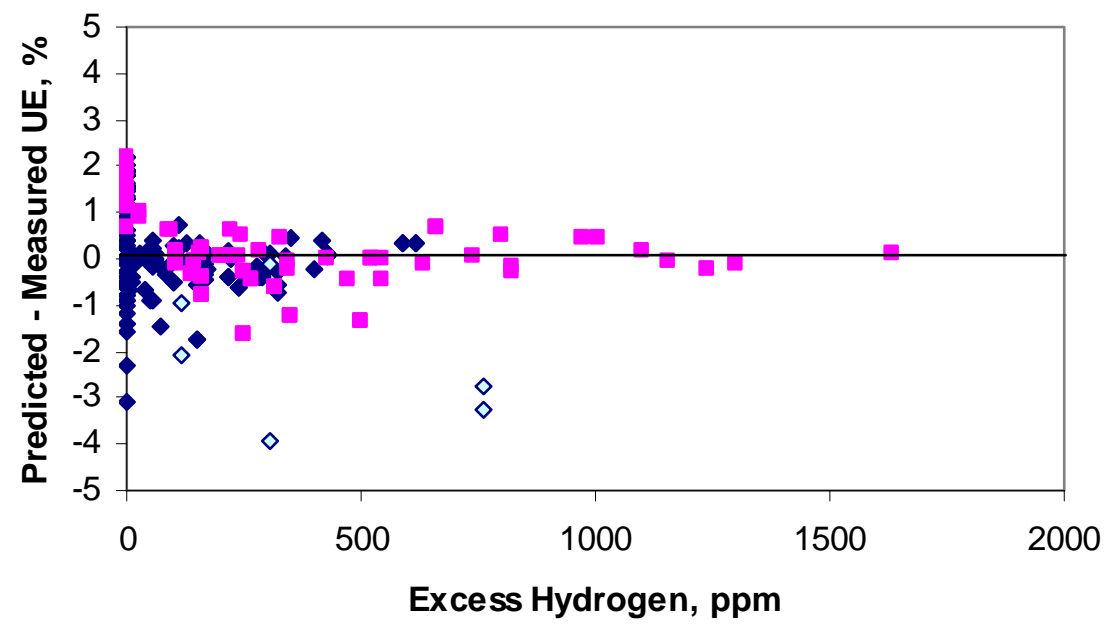

- Axial Tests $\backsim$ Burst Tests $\diamond$ ANL Axial Tests

Figure 17: Predicted minus measured uniform elongation from irradiated samples from the PNNL database as a function of excess hydrogen $\left(293 \mathrm{~K} \leq \mathrm{T} \leq 755 \mathrm{~K}\right.$ and $0 \leq \Phi \leq 14 \times 10^{25}$ $\left.\mathrm{n} / \mathrm{m}^{2}\right)$. 


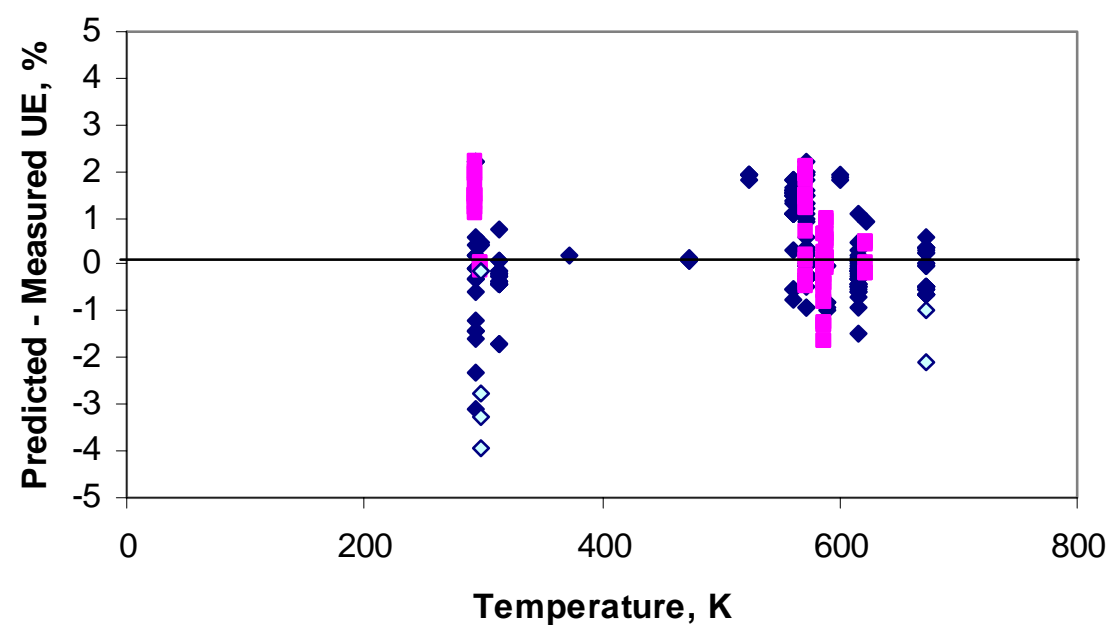

- Axial Tests $\backsim$ Burst Tests $\diamond$ ANL Axial Tests

Figure 18: Predicted minus measured uniform elongation from irradiated samples from the PNNL database as a function of temperature $\left(0 \leq \Phi \leq 14 \times 10^{25} \mathrm{n} / \mathrm{m}^{2}\right.$ and $0 \leq \mathrm{H}_{\mathrm{ex}} \leq 850$ ppm).

\section{$\underline{3.4 \text { Stress vs. Strain Curves }}$}

One of the reports from the PNNL database of Zircaloy mechanical properties ${ }^{9} \operatorname{contained}^{-}$ four examples of measured stress vs. strain curves from uniaxial tube tensile tests. These curves were compared to the stress vs. strain curve using the power law that has been adjusted to fit the yield stress and ultimate tensile strength values in the PNNL database.

It should be noted that the measured stress vs. strain curves are engineering stress and strain, while the predicted curves are true stress and strain. Below the uniform elongation, there is little reduction of area; therefore, theoretically, these two quantities should be very close. At higher strain values, necking begins and reduction of area causes a large difference between engineering stress and strain and true stress and strain. It is not possible to calculate the true stress from the load vs. displacement data because reduction of area is not measured as a function of displacement. It would be possible to make this measurement, but it has not been made for the data contained in the PNNL database. Because of this, the data and predictions will only be compared up to the uniform elongation value.

Figures 19 - 22 show the measured and predicted stress vs. strain curves, for axial tube tension samples taken at three different temperatures. The solid line in this figure is the model prediction, the dotted line is the measured stress/strain curve calculated from the load vs. displacement measurement, and the squares are the measured $0.2 \%$ yield stress (YS) and stress at maximum load (UTS). 


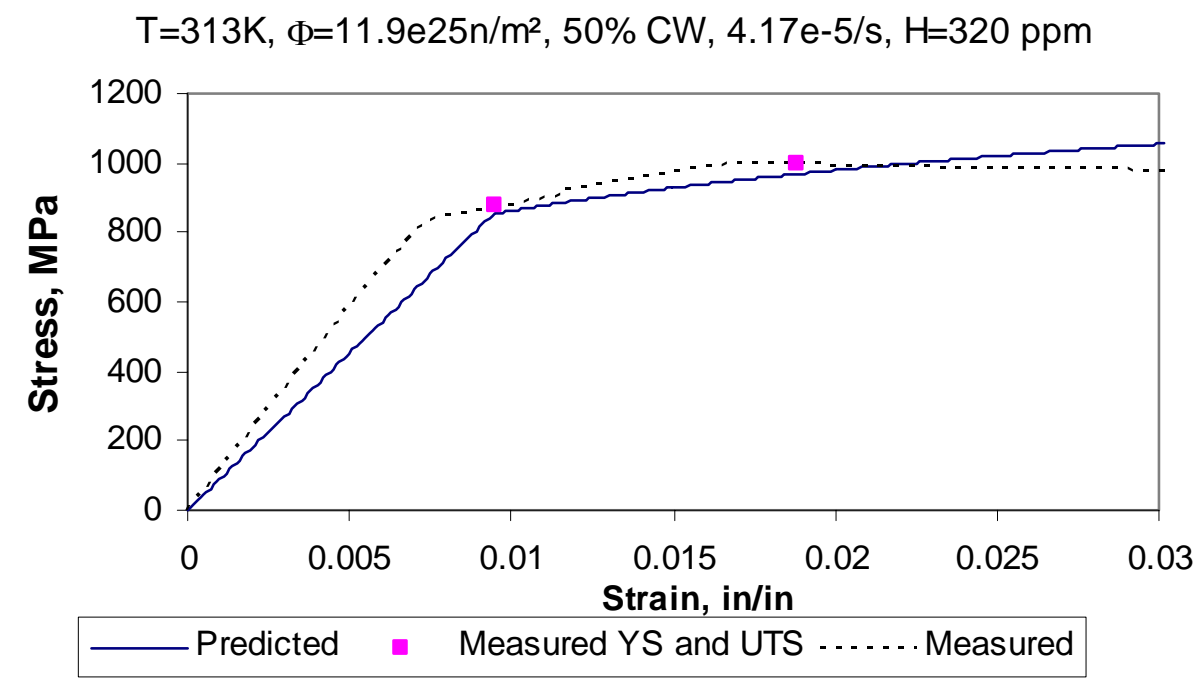

Figure 19: Stress vs. strain curves for uniaxial tube sample (PWR) taken at $313 \mathrm{~K}$ $\left(40^{\circ} \mathrm{C}\right)$.

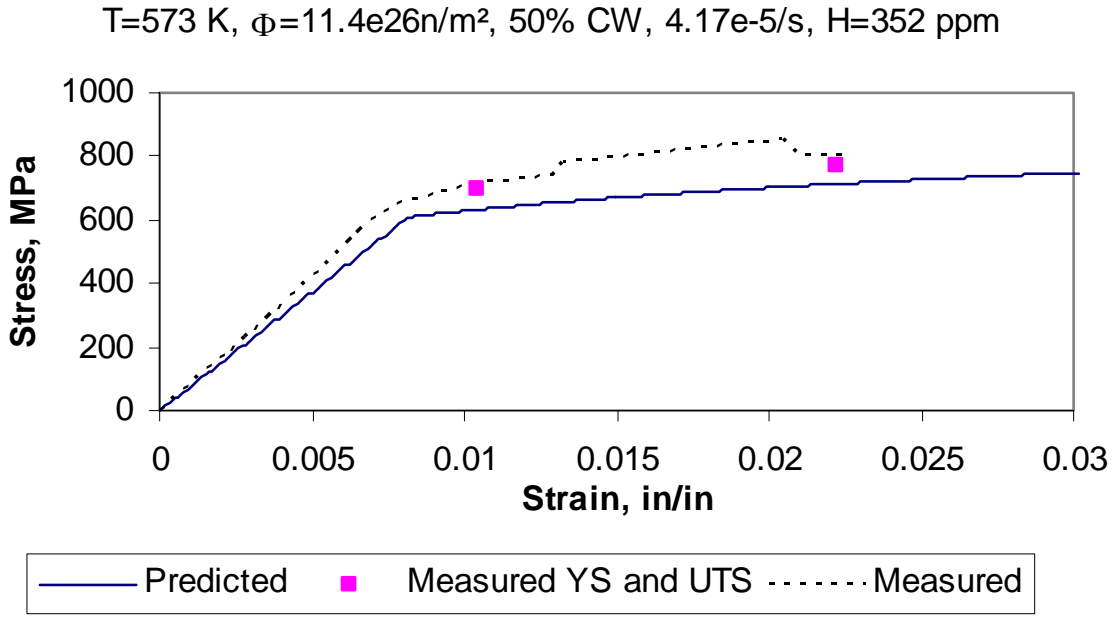

Figure 20: Stress vs. strain curves for uniaxial tube sample (PWR) taken at 573K $\left(300^{\circ} \mathrm{C}\right)$. 


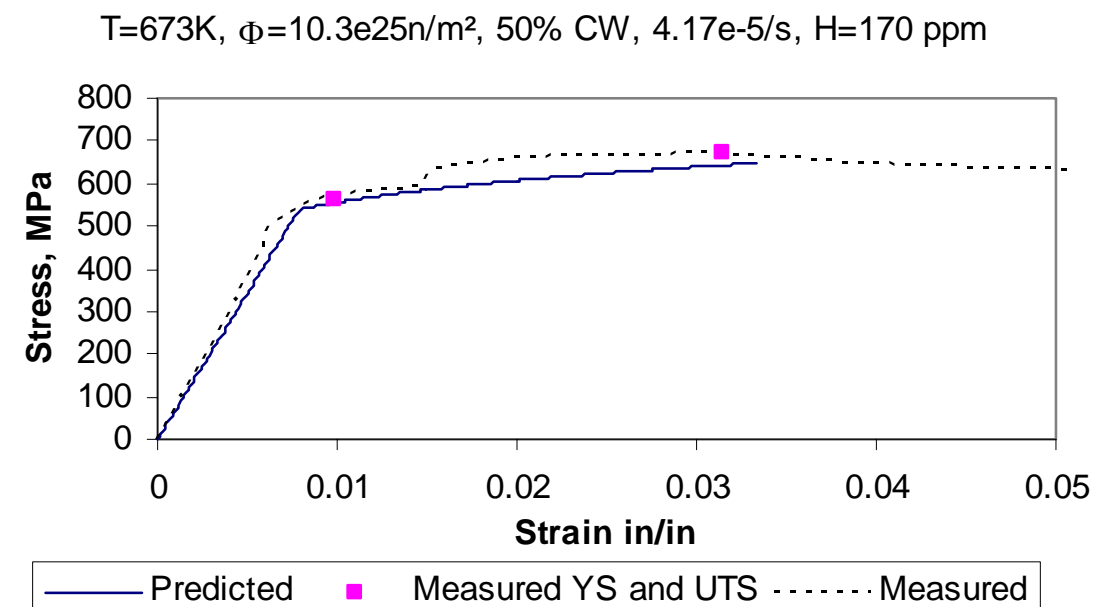

Figure 21: Stress vs. strain curves for uniaxial tube sample (PWR) taken at $673 \mathrm{~K}$ $\left(400^{\circ} \mathrm{C}\right)$.

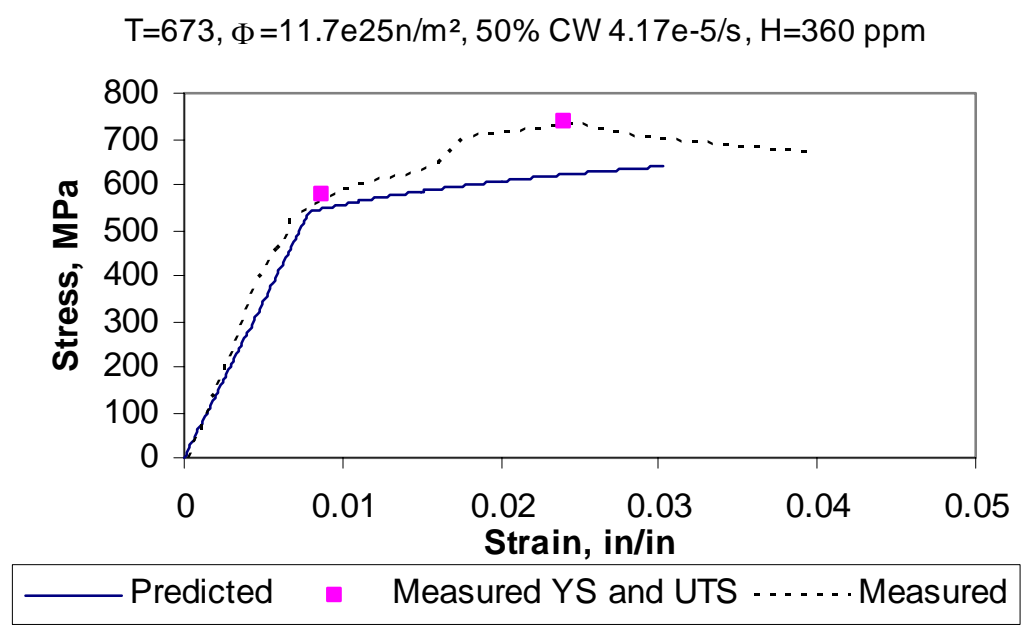

Figure 22: Stress vs. strain curves for uniaxial tube sample (PWR) taken at $673 \mathrm{~K}$ $\left(400^{\circ} \mathrm{C}\right)$.

It can be seen from these figures that the power law with the new mechanical model fitted parameters predicts these four curves reasonably well for PWR-type cladding (cold worked stress relieved). The largest discrepancy comes in Figure 22. However, it should be noted that the conditions for the tests in Figures 21 and 22 are identical, and the model predicts the test in Figure 21 reasonably well. This demonstrates that there is some degree of scatter in this data. 


\section{$\underline{3.5 \text { Ring Stretch Tests }}$}

Figures 23 and 24 show predicted vs. measured yield stress and ultimate tensile strength for all the data from the PNNL database including the ring stretch tests. The data from the ring tests were not used to develop this model, but in comparing them to the new model it can be seen that the new model predicts the ring test yield and ultimate tensile data as well as the data from the axial tension test and the biaxial burst tests. The scatter in the ring test data is about the same as the scatter in the other data sets. The standard deviation for yield stress including the axial tension tests, biaxial burst tests, and ring stretch tests is $67 \mathrm{MPa}$, which is about the same as the standard deviation for only the axial tension tests and biaxial burst tests. The standard deviation for ultimate tensile strength including the axial tension tests, biaxial burst tests, and ring stretch tests is 70 $\mathrm{MPa}$, which is slightly lower than the standard deviation for only the axial tension tests and biaxial burst tests. Based on this comparison it appears that the ring stretch tests are as accurate for determining yield stress and ultimate tensile strength as axial tension tests and biaxial burst tests. It is noted that there is considerable scatter in the ANL ring stretch test yield stress data at high fluence. These data are not included in the above calculations of standard deviation

Figure 25 shows the predicted minus measured uniform elongation from irradiated cladding as a function of excess hydrogen for all the data from the PNNL database including the ring stretch tests. It can be seen from this figure that the strain data from ring stretch tests displays larger strains than the strain data from axial tension tests or biaxial burst tests. The higher uniform elongation strains measured in the ring tests are attributed to the large bending stress and strains of the ring specimens when plastic deformation is experienced. For this reason, the strain data from the ring stretch tests were not included in the uniform elongation model development.

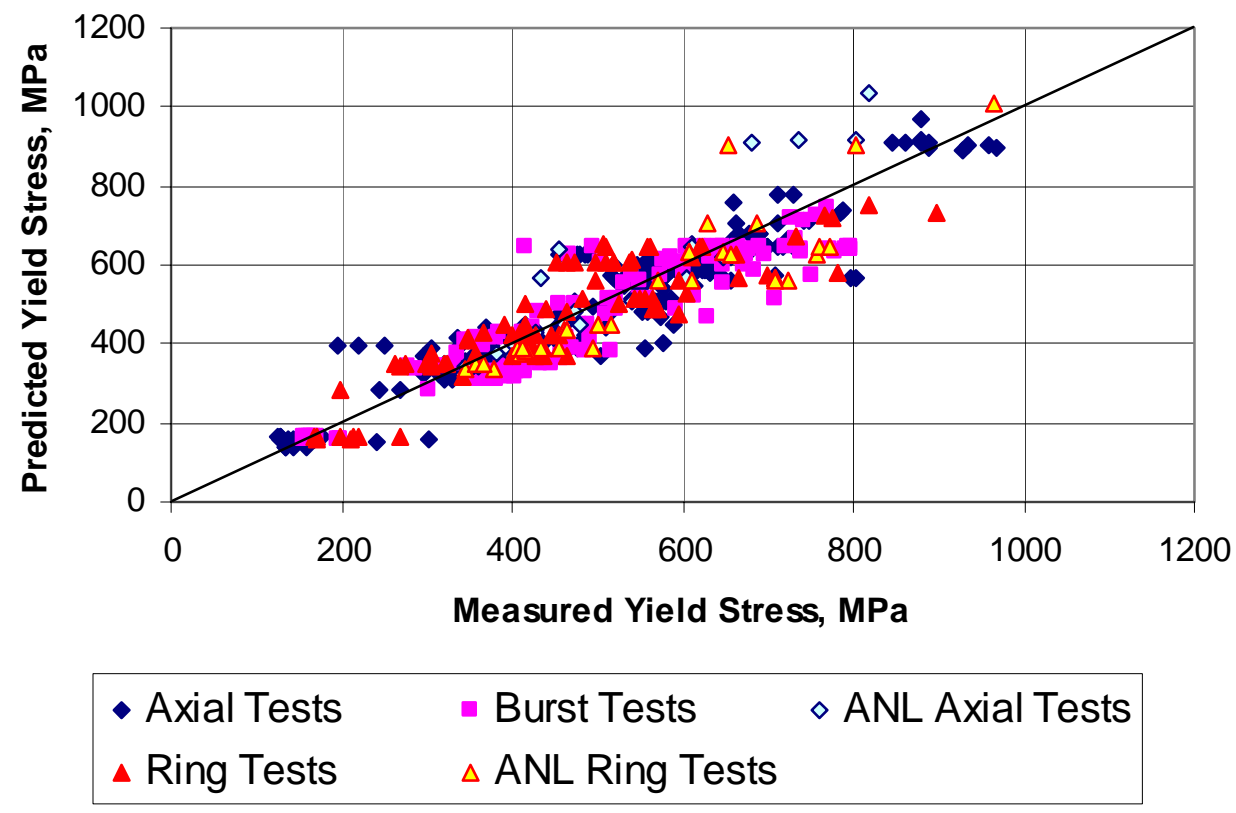

Figure 23: Predicted vs. measured yield stress from the PNNL database 


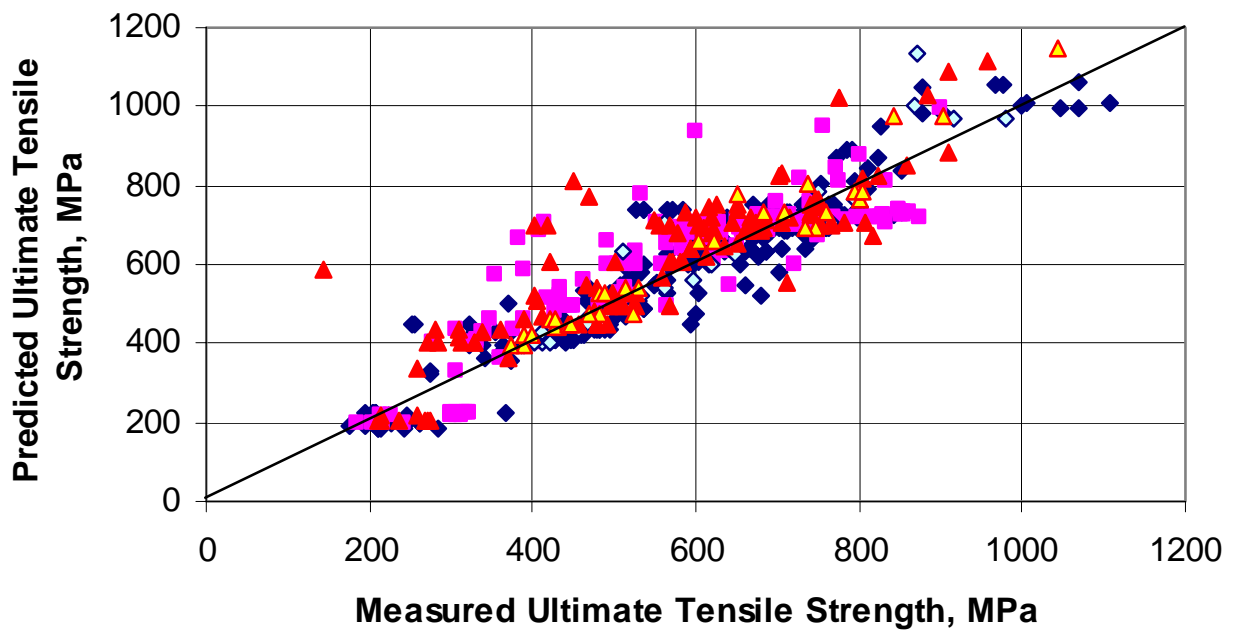

$\begin{array}{ll}- \text { Axial Tests } & - \text { Burst Tests } \\ \Delta \text { Ring Tests } & \triangle \text { ANL Ring Tests }\end{array}$

Figure 24: Predicted vs. measured ultimate tensile strength from the PNNL database

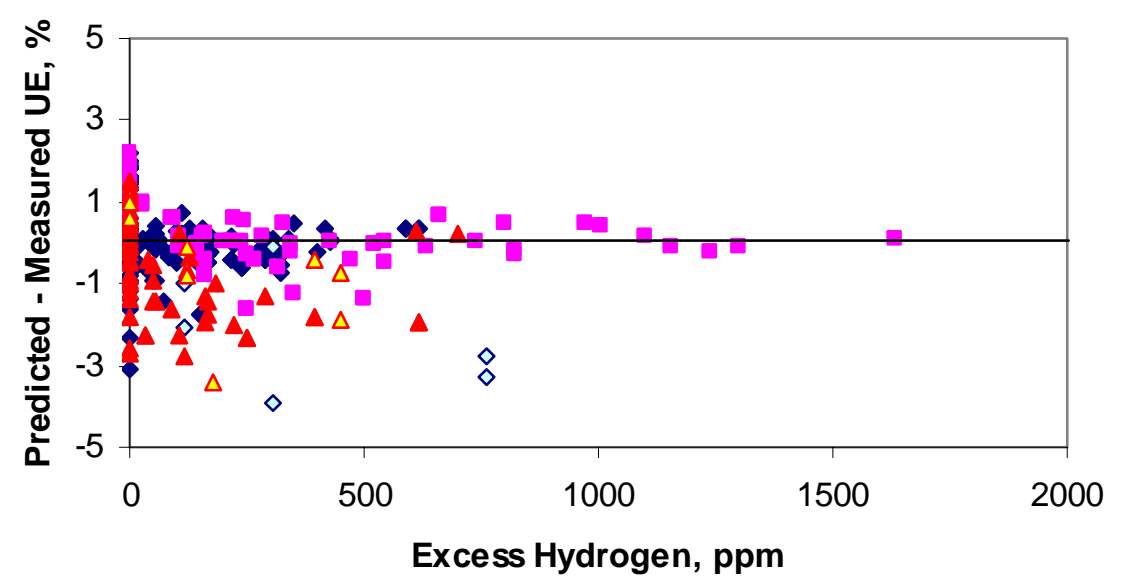

$\begin{array}{ll}- \text { Axial Tests } & \quad \text { Burst Tests } \diamond \text { ANL Axial Tests } \\ \Delta \text { Ring Tests } & \triangle \text { ANL Ring Tests }\end{array}$

Figure 25: Predicted minus measured uniform elongation from irradiated cladding as a function of excess hydrogen from the PNNL database

\section{$\underline{3.6 \text { Independent Data }}$}

Some data have been added to the database of mechanical properties after the model parameters for the mechanical properties were $\operatorname{set}^{29,31-33}$. These data can be used as an independent assessment of the model predictions. These data consist of axial tensile tests on full cladding tubes and ring tests with no machined gage section taken on irradiated RXA Zircaloy-2 and Zircaloy-4 and SRA ZIRLO ${ }^{\mathrm{TM}}$ cladding. The data from Zircaloy was included in all the previous figures. Figures 26 and 27 show the measured and 
predicted yield stress and ultimate tensile strength for all these data with the independent Zircaloy and ZIRLO ${ }^{\mathrm{TM}}$ data shown separately. Figure 28 shows the predicted minus measured uniform elongation as a function of excess hydrogen with the independent Zircaloy and ZIRLO ${ }^{\mathrm{TM}}$ data shown separately.

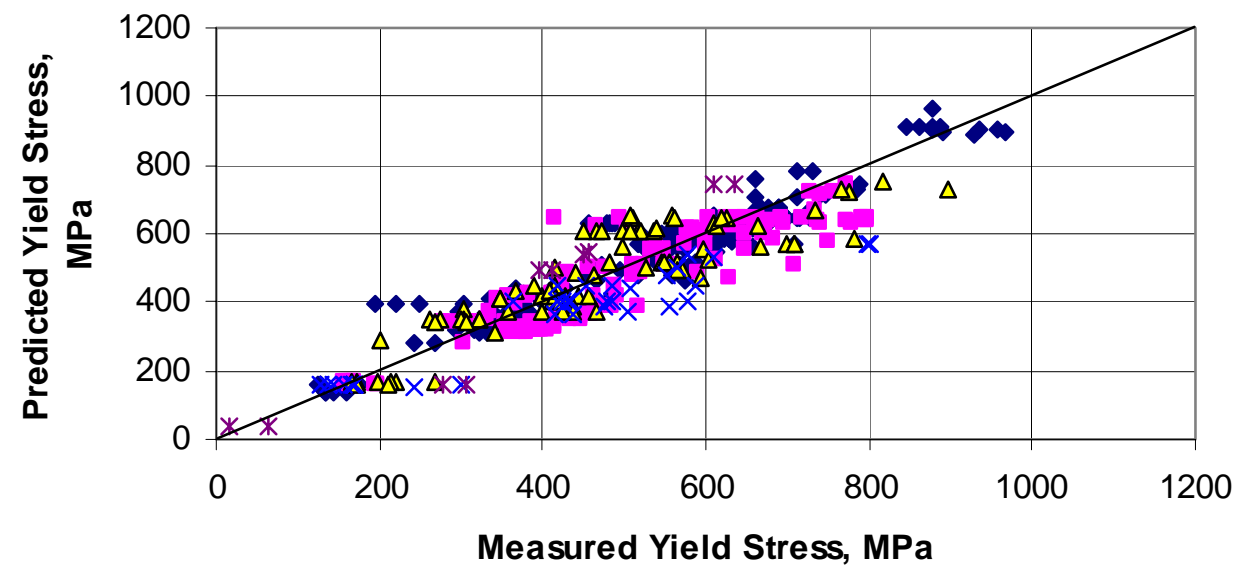

\begin{tabular}{|ll|}
\hline - Axial Tests & Burst Tests \\
$\Delta$ Ring Tests & $x$ Independent Zircaloy Data \\
* Independent ZIRLO Data & \\
\hline
\end{tabular}

Figure 26: Predicted vs. measured yield stress from the PNNL database with the independent data shown separately.

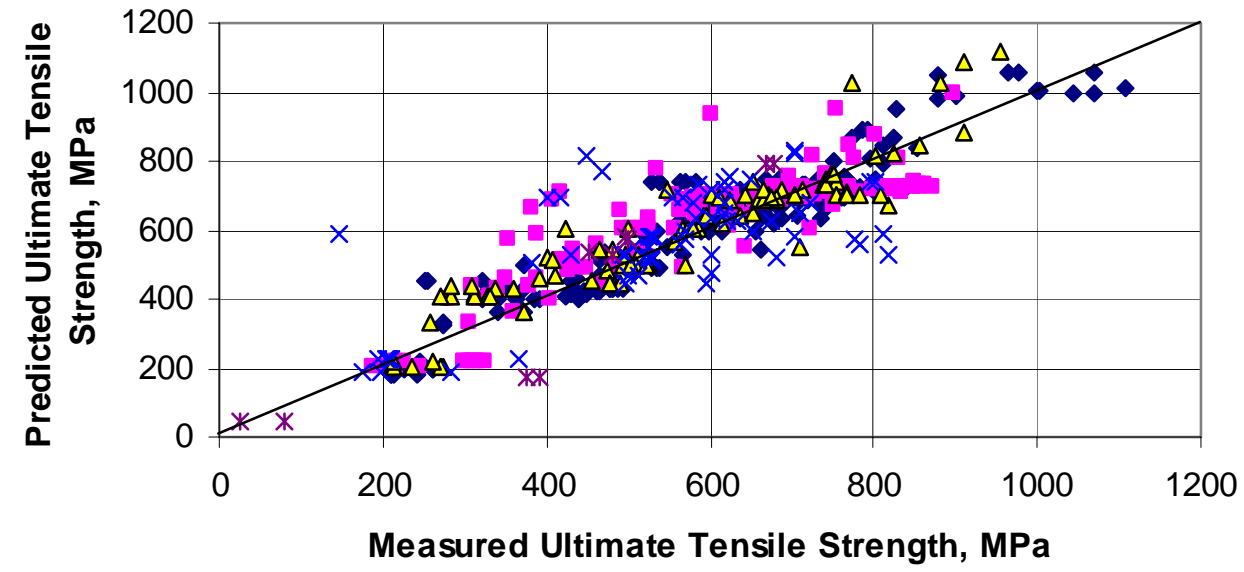

\begin{tabular}{|ll|}
\hline - Axial Tests & Burst Tests \\
$\Delta$ Ring Tests & $x$ Independent Zircaloy Data \\
* Independent ZIRLO Data & \\
\hline
\end{tabular}

Figure 27: Predicted vs. measured ultimate tensile strength from the PNNL database with the independent data shown separately. 


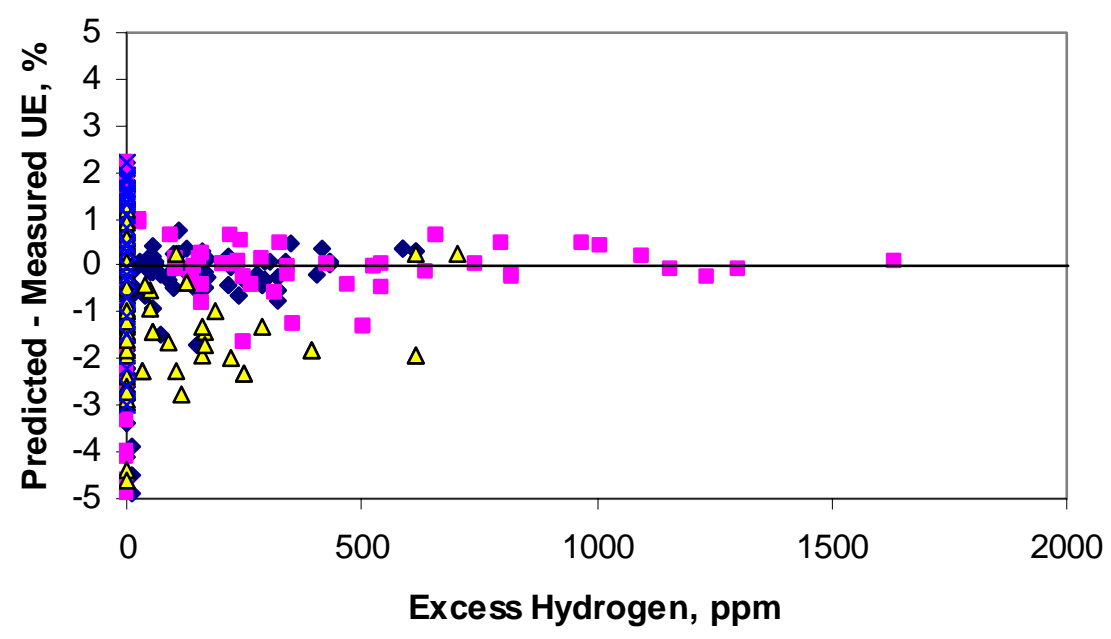

- Axial Tests $\approx$ Burst Tests $\Delta$ Ring Tests $\times$ Independent Zircaloy Data

Figure 28: Predicted minus measured uniform elongation from irradiated samples from the PNNL database as a function of excess hydrogen with the independent data shown separately.

These figures demonstrate that the model predicts the independent data as well as the data that were used to develop the models.

\section{$\underline{3.7 \text { Recrystallized Zircaloy data }}$}

The data comparisons shown above are for cold worked, stress relief annealed (SRA) and fully recrystallized (RXA) Zircaloy-4 and Zircaloy-2. However, if only the RXA data is examined it is apparent that while the model predicts the RXA data well, there is a distinct lack of RXA data at high fluence $\left(>5 \times 10^{25} \mathrm{n} / \mathrm{m}^{2}\right)$ and high hydrogen level (>200 ppm). Mechanical data from RXA cladding is important in order to accurately model BWR cladding performance at high burnup.

Figures 29 and 30 show the predicted minus measured yield stress and ultimate tensile strength, respectively, as a function of fast neutron fluence for RXA cladding. The lack of high fluence data can be seen in these figures. Samples with high excess hydrogen concentration $(>600 \mathrm{ppm})$ are noted in Figure 30. Figure 31 shows the predicted minus measured uniform elongation as a function of excess hydrogen concentration for RXA cladding. It can be seen that there are only a few data points from RXA cladding at high hydrogen concentration. Figure 32 shows the predicted minus measured uniform elongation as a function of temperature for RXA cladding. It can be seen that although these data bound the temperature range of the database, there is relatively little data available for recrystallized cladding. 


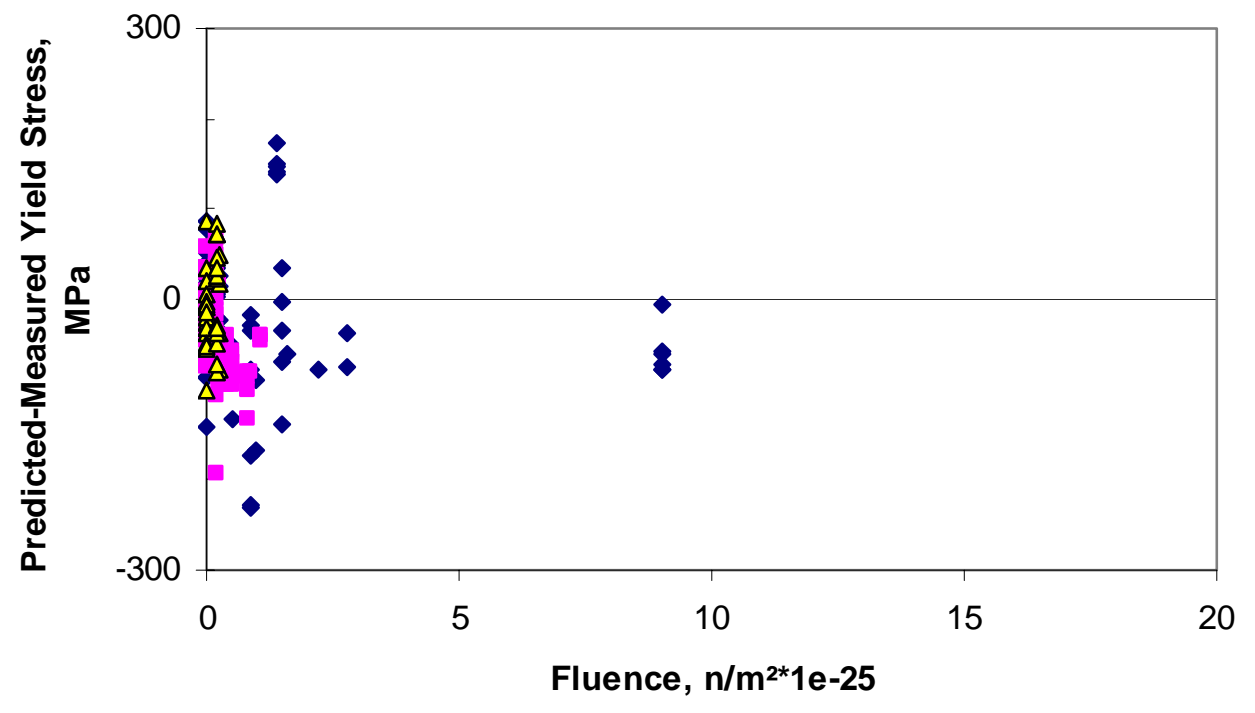

- Axial Tests - Burst Tests $\Delta$ Ring Tests

Figure 29: Predicted minus measured yield stress from RXA cladding as a function of fluence $\left(293 \mathrm{~K} \leq \mathrm{T} \leq 673 \mathrm{~K}\right.$ and $\left.0 \leq \mathrm{H}_{\mathrm{ex}} \leq 100 \mathrm{ppm}\right)$

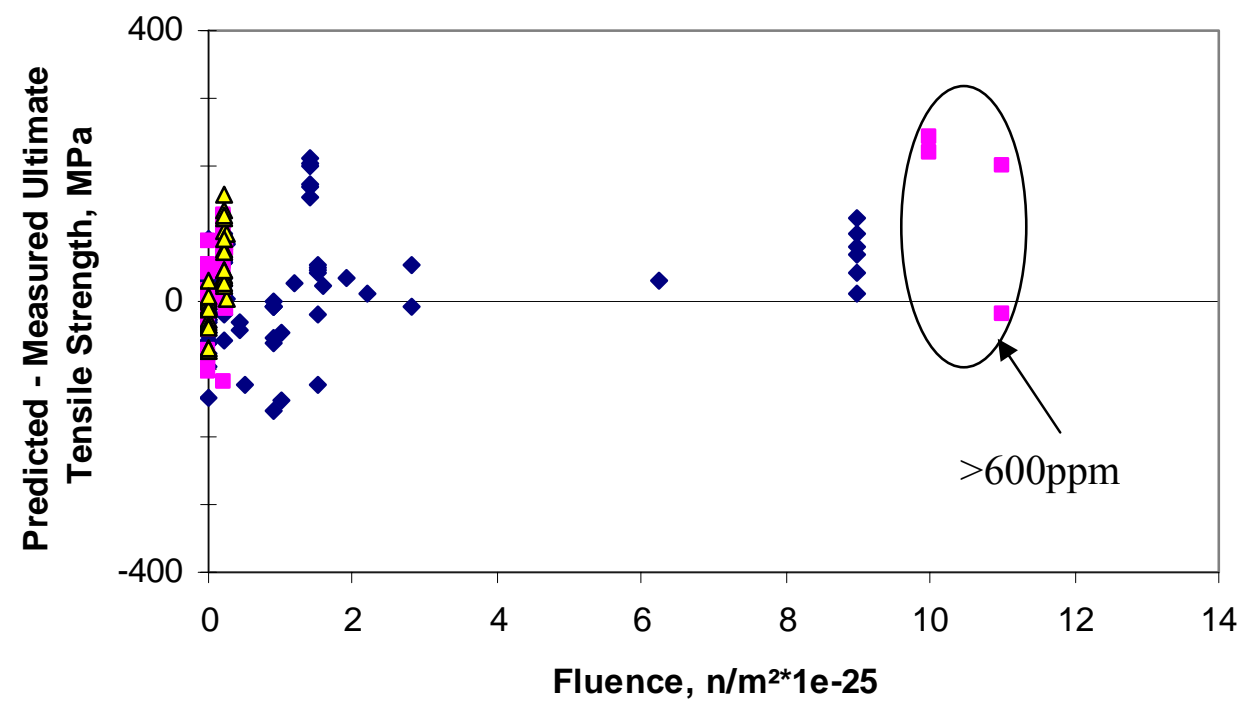

- Axial Tests - Burst Tests $\Delta$ Ring Tests

Figure 30: Predicted minus measured ultimate tensile strength from RXA cladding as a function of fluence $\left(293 \mathrm{~K} \leq \mathrm{T} \leq 673 \mathrm{~K}\right.$ and $0 \leq \mathrm{H}_{\mathrm{ex}} \leq 100 \mathrm{ppm}$ (except as marked)) 


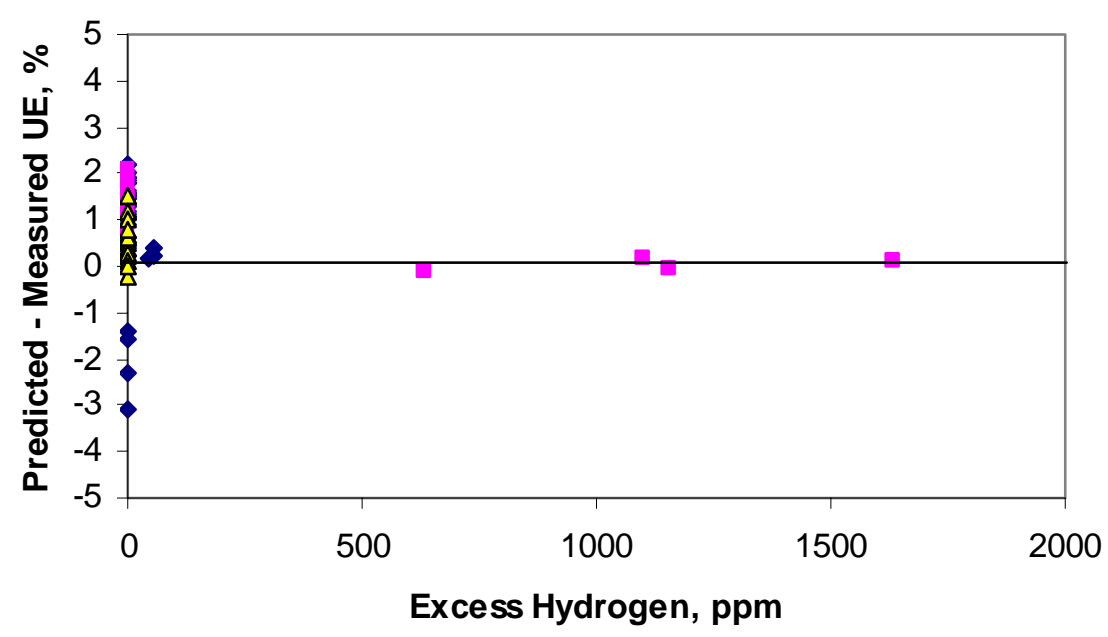

- Axial Tests - Burst Tests $\Delta$ Ring Tests

Figure 31: Predicted minus measured uniform elongation from RXA cladding as a function of excess hydrogen $\left(293 \mathrm{~K} \leq \mathrm{T} \leq 673 \mathrm{~K}\right.$ and $\left.0 \leq \Phi \leq 9 \times 10^{25} \mathrm{n} / \mathrm{m}^{2}\right)$

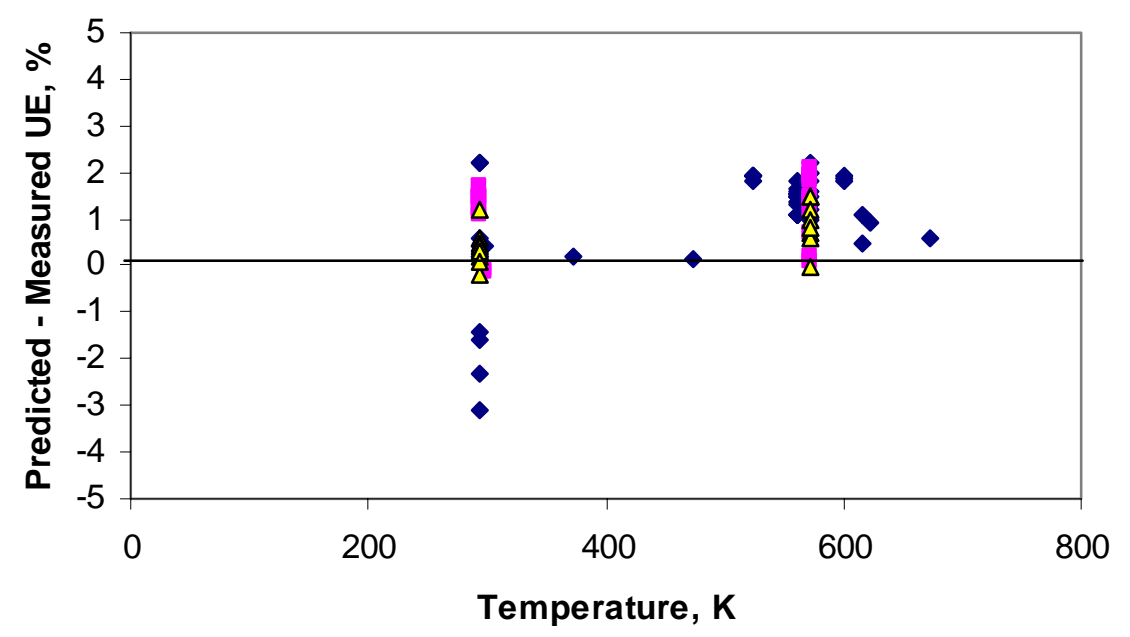

- Axial Tests $\approx$ Burst Tests $\Delta$ Ring Tests

Figure 32: Predicted minus measured uniform elongation from RXA cladding as a function of temperature

\section{Gage Length and Width Effects}

Examination of material property databases containing data collected from a number of test conditions and configurations often reveals disparity between samples extracted from equivalent materials due to specimen geometry. Figure 33 shows the geometry of the samples considered in this report. One example of a different due to specimen geometry is the ANL data. In the case of irradiated Zircaloy samples, experimental measurements of strain exhibit a strong dependency on specimen gage length and width as discussed by Williams ${ }^{29}$. This dependency is characterized by a decrease or increase in uniform 
elongation with increasing gage length or width, respectively, for samples of equivalent material.<smiles>C1=C=C=C=CC=C=C=C=1</smiles>

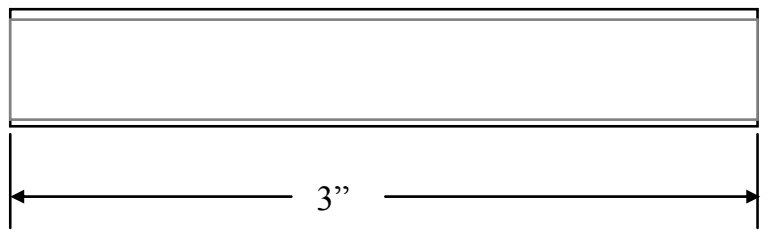

Full tube axial tension sample and biaxial burst sample

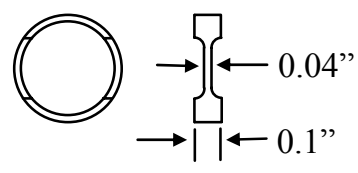

ANL Ring stretch sample

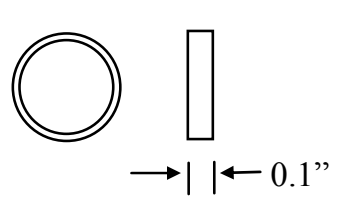

Standard ring stretch sample

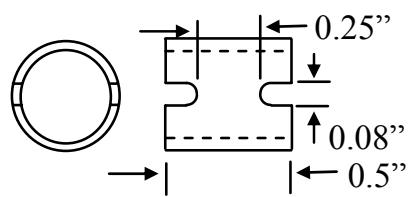

PSU plane strain sample<smiles>C1=CC=CC=CC=C1</smiles>

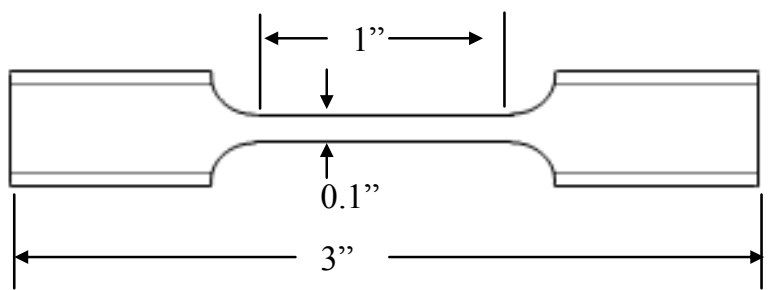

ANL axial tension sample

Figure 33: Geometry of samples considered in this report. Note that inner and outer diameters are not shown here and vary with fuel rod design.

Decreased uniform elongation in irradiated samples of equivalent material with longer gage lengths is attributed to a deformation mechanism known as dislocation channeling ${ }^{29}$. As stress-induced dislocation motion is initiated, dislocations interact with irradiationinduced defect loops, dragging them from preferred crystallographic slip planes and creating defect-free pathways, or channels, for additional dislocation motion ${ }^{30}$.

Dislocations propagate along these channels, leading to the development of highly localized plastic strains between grains, before reaching the edge of the specimen where they cause large deformation offsets ${ }^{31}$. Therefore, the width of the gage section plays an important role in the uniform elongation because dislocation channels are more likely to propagate into the lower stress regions near the grips in wider specimens instead of reaching an edge of the specimen and resulting in plastic instability ${ }^{31}$. Given the typical texture of Zircaloy, where the relation between crystal orientation and available deformation modes normally inhibit deformation in the thickness direction of sheets and tubing ${ }^{31}$, necking occurs within deformation bands traversing the specimen width ${ }^{29}$. Therefore, in a structural component having this texture but having a large width 
perpendicular to the direction of applied stress, resistance to necking of this type will be high; thus the capacity for uniform strain in large sections may be expected to be higher than for standard uniaxial tensile test specimens ${ }^{29}$. Despite the large extents of plastic deformation that occur within the dislocation channels, the overall elongation of specimens with smaller gage widths perpendicular to the direction of applied stress is low. Microscopic stresses evolve to accommodate the highly localized plastic strain between the grains, leading to kinematic hardening and loss of ductility ${ }^{30}$. As a result, specimens with larger gage length to width ratios, such as standard uniaxial tensile specimens, routinely exhibit less uniform elongation than those with smaller gage length to width ratios, such as plane strain tensile specimens, when equivalent materials are analyzed.

Overall, the literature regarding uniform elongation measurement of irradiated Zircaloy samples indicates that gage length and width effects should be considered whenever strain data from different specimen test configurations are being compared. A linear relationship between the failure strain and the ratio of the square root of the sample gage length and the loaded cross sectional area has been observed, providing a possible means for interpreting strain data collected from differently sized test specimens ${ }^{20}$.

Nevertheless, it is important to note that local strains determined from various test configurations are not material properties as they are strongly affected by specimen geometry $^{31}$. Therefore, in order to apply strain data to in-service application, the specimen geometry must be prototypic of the in-service application ${ }^{31}$.

All of the axial tensile test data that are in the PNNL database are taken on full tube sections that have been de-fueled. In contrast, the ANL data are taken from tube samples where everything but two narrow dogbone shapes have been machine away. This may explain the lower stress and higher strain data than expected from the irradiated ANL samples. Although a test was performed to demonstrate that this geometry gave similar results to the traditional geometry on unirradiated samples, no similar test was performed on irradiated material. Given the different deformation mechanisms observed in irradiated Zircaloy, a similar test should be done using irradiated material before data from the dogbone geometry are used. Until such a test is done, and given the disparity between the ANL data and the data in the PNNL database, the ANL data will be left out of these model comparisons.

\section{Application of Material Property Models to Spent Fuel Cladding Analyses}

This section will discuss the range of operating conditions that the material property data are applicable to for modeling spent fuel cladding from PWRs and BWRs. The range of SRA Zircaloy-4 property data is fairly extensive in terms of fluence and hydrogen levels due to corrosion as shown in Figure 2. The temperature range of the SRA property data extends from room temperature up to $755 \mathrm{~K}$, however, there is little data above $673 \mathrm{~K}$ and it is not recommended to apply the properties above $673 \mathrm{~K}$.

The range of RXA Zircaloy data is very sparse as shown in Figure 2. The data at high hydrogen and fluence levels are from RXA Zr-4 guide tubes that have a uniform 
distribution of hydrogen that is not typical of BWR RXA fuel cladding. BWR RXA cladding usually has most of the hydrogen located as a rim of hydrides at the OD and/or liner ID of the cladding. The hydride rims are very brittle and act as crack initiation points that can reduce the ductility. Due to the lack of mechanical data for RXA BWR fuel cladding there is a large uncertainty in their mechanical properties and due to the lack of data it is difficult to quantitatively estimate uncertainties. In addition, hydrides in RXA cladding appears to have a more random orientation than SRA cladding such that some hydrides are orientated in the radial direction that may result in lower ductilities (uniform elongation) than SRA material at an equivalent excess hydrogen level. Therefore, an engineering judgement is made that the uncertainties in the RXA data are a factor of 2 larger than those for SRA mechanical properties with fast fluences and excess hydrogen levels above $3 \times 10^{25}$ $\mathrm{n} / \mathrm{m}^{2}$ and $100 \mathrm{ppm}$, respectively.

The cladding fluence levels in high burnup fuel rods have very limited variability (narrow range) for normal operation in both PWRs and BWRs as shown in Table 1. For example, at a local burnup of $60 \mathrm{GWd} / \mathrm{MTU}$ the fast fluence can vary between 10 to $11 \times 10^{25} \mathrm{n} / \mathrm{m}^{2}$ for a PWR and 9 to $10.5 \times 10^{25} \mathrm{n} / \mathrm{m}^{2}$ for a BWR depending on fuel management. However, cladding corrosion and hydrogen levels can have a much larger variation depending on the cladding material, coolant chemistry, the cycle and even variation within the same cycle between fuel rods. For example, the corrosion (and hydrogen) levels at a burnup of $60 \mathrm{GWd} / \mathrm{MTU}$ for low tin SRA Zircaloy-4 in a PWR can vary between 50 to $100 \mu \mathrm{m}$ of oxide ( 400 to $800 \mathrm{ppm}$ of total hydrogen) depending on whether the fuel is from a low or high duty plant. For a BWR fuel with current generation RXA Zircaloy-2 cladding at a burnup of $60 \mathrm{GWd} / \mathrm{MTU}$ the uniform oxide levels can vary between 20 to $45 \mu \mathrm{m}$ ( $\sim 100$ to $220 \mathrm{ppm}$ of hydrogen). Therefore, the greatest variability between the mechanical data is in ductility (measured as uniform elongation). This is also evident from examination of the uniform elongation data at a given test temperature and burnup level.

A spent fuel cask can have a wide variety of different fuel with different burnups such that the analyses should attempt to account for this variation or perform bounding analyses. The two variables that are omitted from Table 1 that can affect the cladding properties are the temperature and the strain rate. These variables will be defined in the accident analysis. These analyses of properties also assume that the hydrogen in the cladding has not reoriented in the radial direction or that hydride blisters are not present. If radially oriented hydrides or hydride blisters are present, they can significantly embrittle the cladding, decreasing the stress and strain required for failure such that the elastic-plastic equations presented in this report are no longer applicable. 
Table 1: Ranges of fast neutron fluence, cladding type, hydrogen concentration, and cold work for PWR and BWR cladding under spent fuel conditions at $66 \mathrm{GWd} / \mathrm{MTU}$

\begin{tabular}{|l|l|l|}
\hline & \multicolumn{1}{|c|}{ PWR } & \multicolumn{1}{c|}{ BWR } \\
\hline Fast neutron fluence & $1.2 \times 10^{26} \mathrm{n} / \mathrm{m}^{2}(\max )$ & $1.2 \times 10^{26} \mathrm{n} / \mathrm{m}^{2}(\mathrm{max})$ \\
\hline Cladding type & Zircaloy-4 & Zircaloy-2 \\
\hline Cladding cold work & $50 \%$ & $0 \%$ \\
\hline Hydrogen concentration & $500 \mathrm{ppm}$ (avg.) & $250 \mathrm{ppm}$ (avg.) \\
\hline
\end{tabular}

In order to show the effect that each of these parameters has on the yield stress, ultimate tensile strength, and the uniform elongation, each of these parameters has been plotted as a function of each variable that it is dependent upon while holding the other variables constant at a given value. Figures $34,35,36$, and 37 present an example of the predicted yield stress for PWR and BWR conditions as a function of temperature, fast neutron fluence, cold work and strain rate, respectively. The standard deviation on these predictions is $\pm 67 \mathrm{MPa}$.

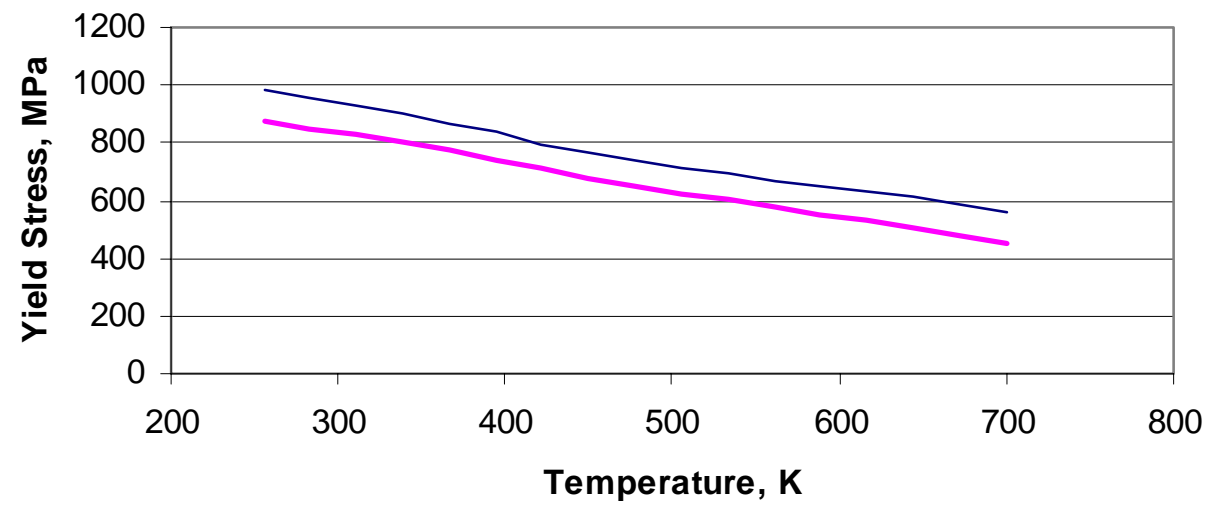

PWR conditions - BWR conditions

Figure 34: Model predictions of yield stress for PWR and BWR conditions as a function of temperature for strain rate of $1 \times 10^{-4} \mathrm{in} / \mathrm{in} / \mathrm{s}$ with other conditions given in Table 1 . 


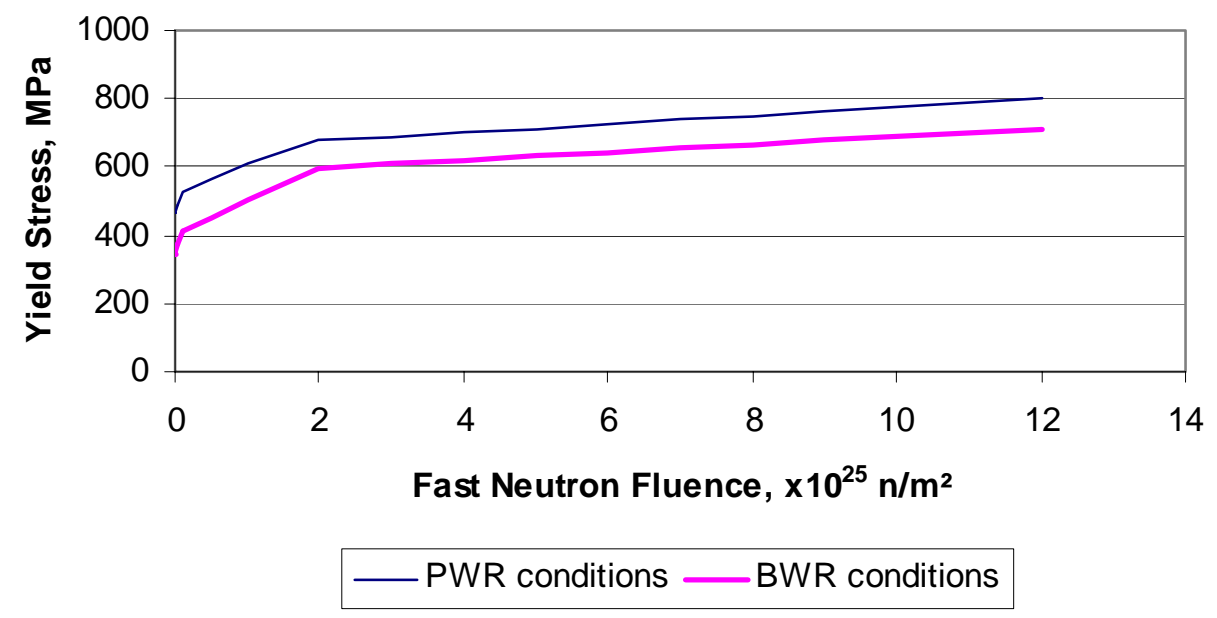

Figure 35: Model predictions of yield stress for PWR and BWR conditions as a function of fast neutron fluence for temperature of $300^{\circ} \mathrm{F}(422 \mathrm{~K})$ and strain rate of $1 \times 10^{-4} \mathrm{in} / \mathrm{in} / \mathrm{s}$ with other conditions given in Table 1.

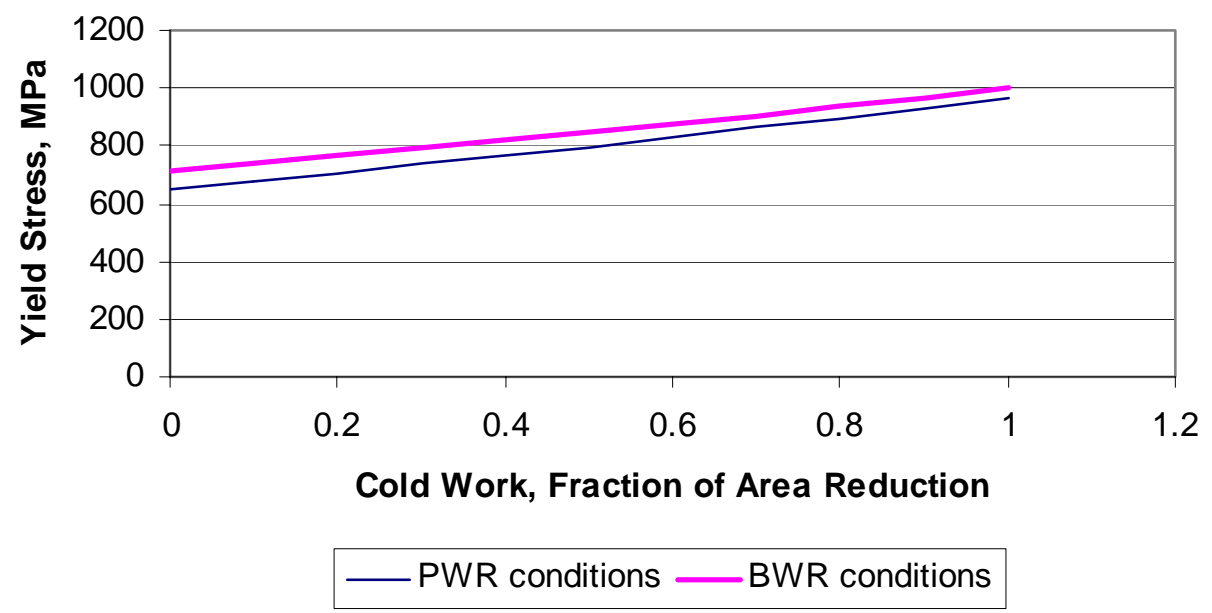

Figure 36: Model predictions of yield stress for PWR and BWR conditions as a function of cold work for temperature of $300^{\circ} \mathrm{F}(422 \mathrm{~K})$ and strain rate of $1 \times 10^{-4} \mathrm{in} / \mathrm{in} / \mathrm{s}$ with other conditions given in Table 1. 


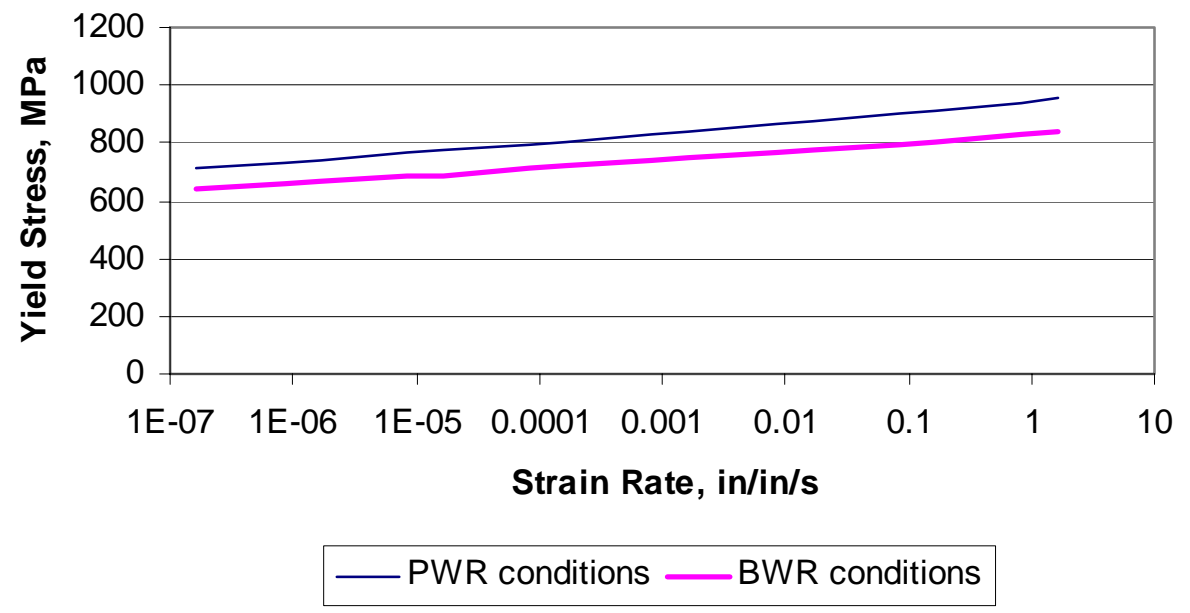

Figure 37: Model predictions of yield stress for PWR and BWR conditions as a function of strain rate for temperature of $300^{\circ} \mathrm{F}(422 \mathrm{~K})$ with other conditions given in Table 1.

Figures 38, 39, 40, 41, and 42 present the predicted ultimate tensile strength for PWR and BWR conditions as a function of those dependent parameters in the model such as temperature, fast neutron fluence, cold work, strain rate, and excess hydrogen, respectively. The standard deviation on these predictions is $\pm 70 \mathrm{MPa}$.

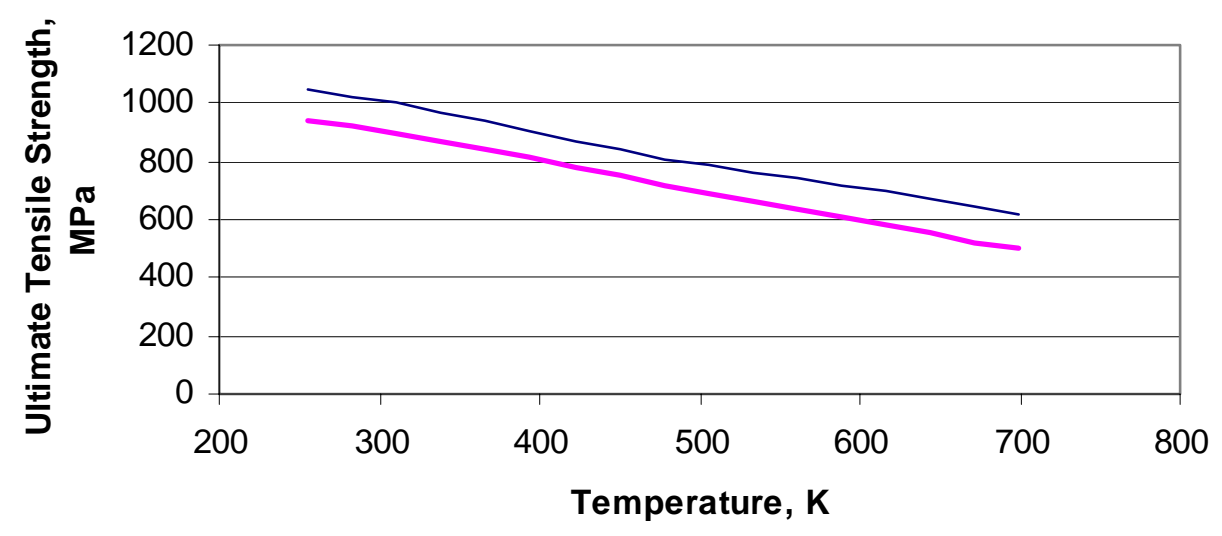

— PWR conditions —BWR conditions

Figure 38: Model predictions of ultimate tensile strength for PWR and BWR conditions as a function of temperature for strain rate of $1 \times 10^{-4} \mathrm{in} / \mathrm{in} / \mathrm{s}$ with other conditions given in Table 1. 


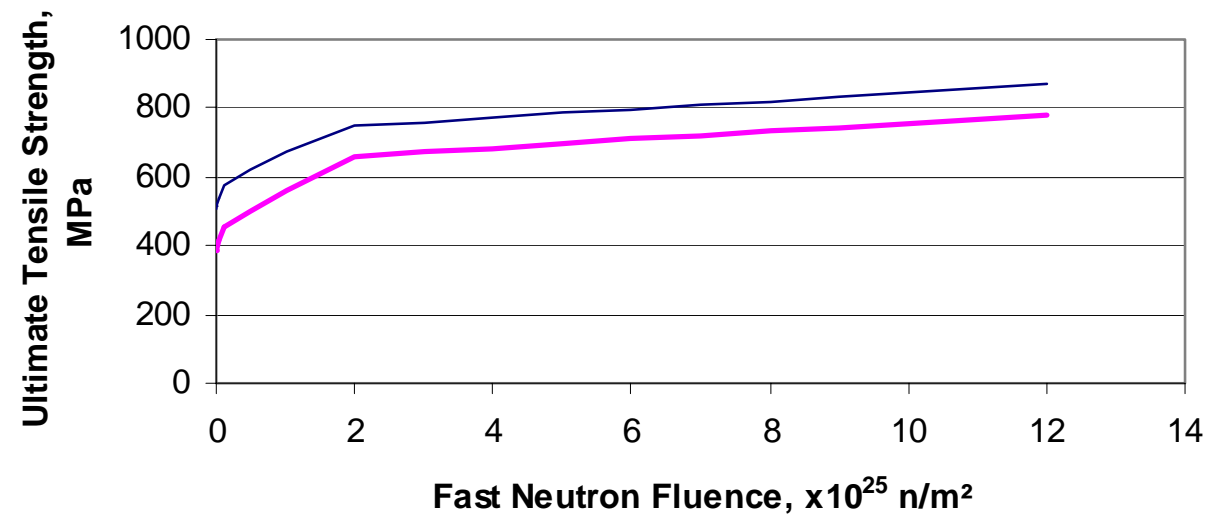

PWR conditions —BWR conditions

Figure 39: Model predictions of ultimate tensile strength for PWR and BWR conditions as a function of fast neutron fluence for temperature of $300^{\circ} \mathrm{F}(422 \mathrm{~K})$ and strain rate of $1 \times 10^{-4} \mathrm{in} / \mathrm{in} / \mathrm{s}$ with other conditions given in Table 1 .

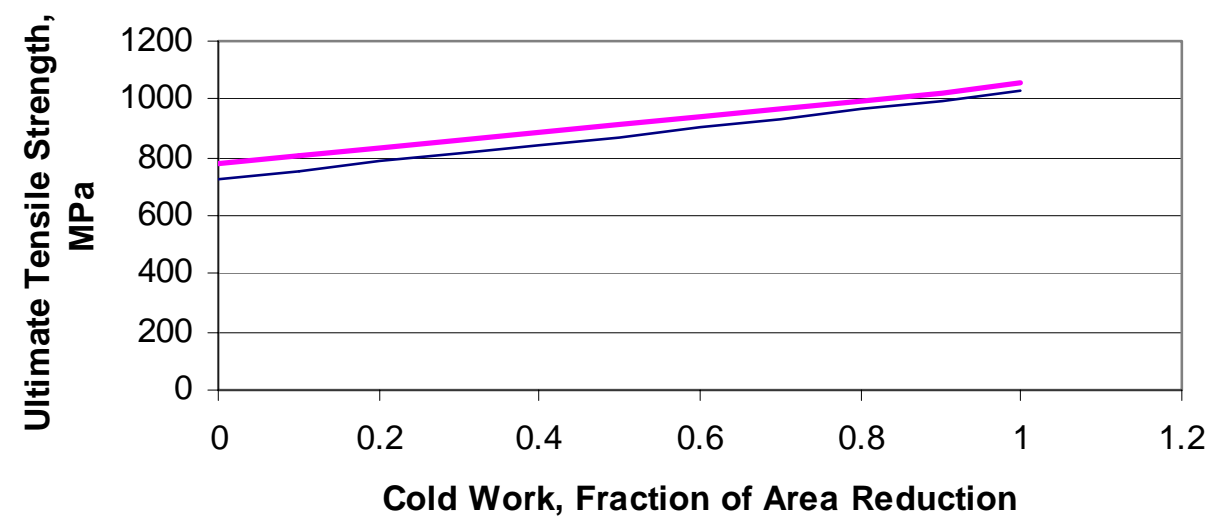

- PWR conditions —BWR conditions

Figure 40: Model predictions of ultimate tensile strength for PWR and BWR conditions as a function of cold work for temperature of $300^{\circ} \mathrm{F}(422 \mathrm{~K})$ and strain rate of $1 \times 10^{-4}$ in/in/s with other conditions given in Table 1. 


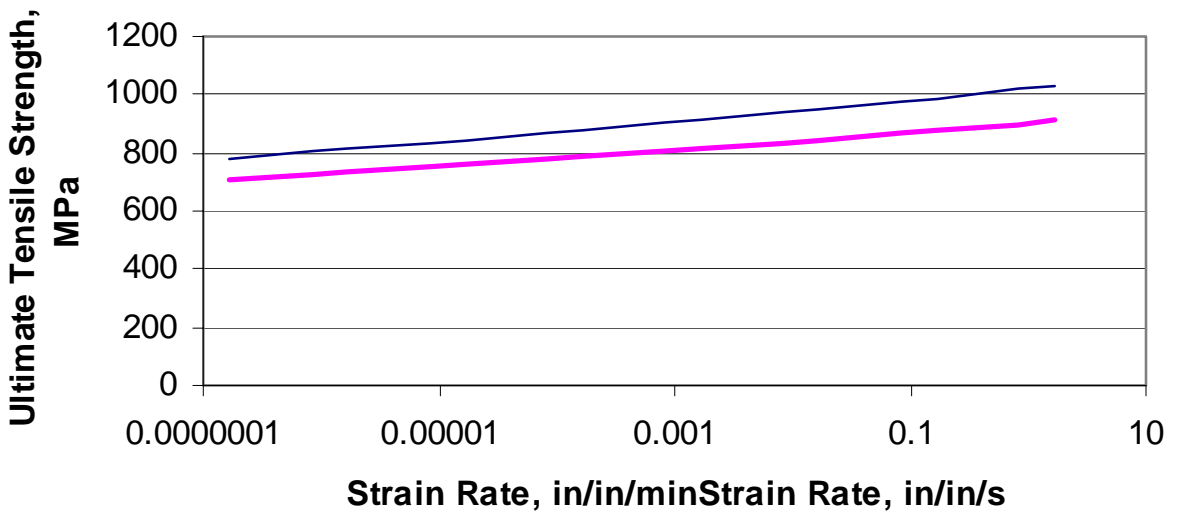

PWR conditions —BWR conditions

Figure 41: Model predictions of ultimate tensile strength for PWR and BWR conditions as a function of strain rate for temperature of $300^{\circ} \mathrm{F}(422 \mathrm{~K})$ with other conditions given in Table 1.

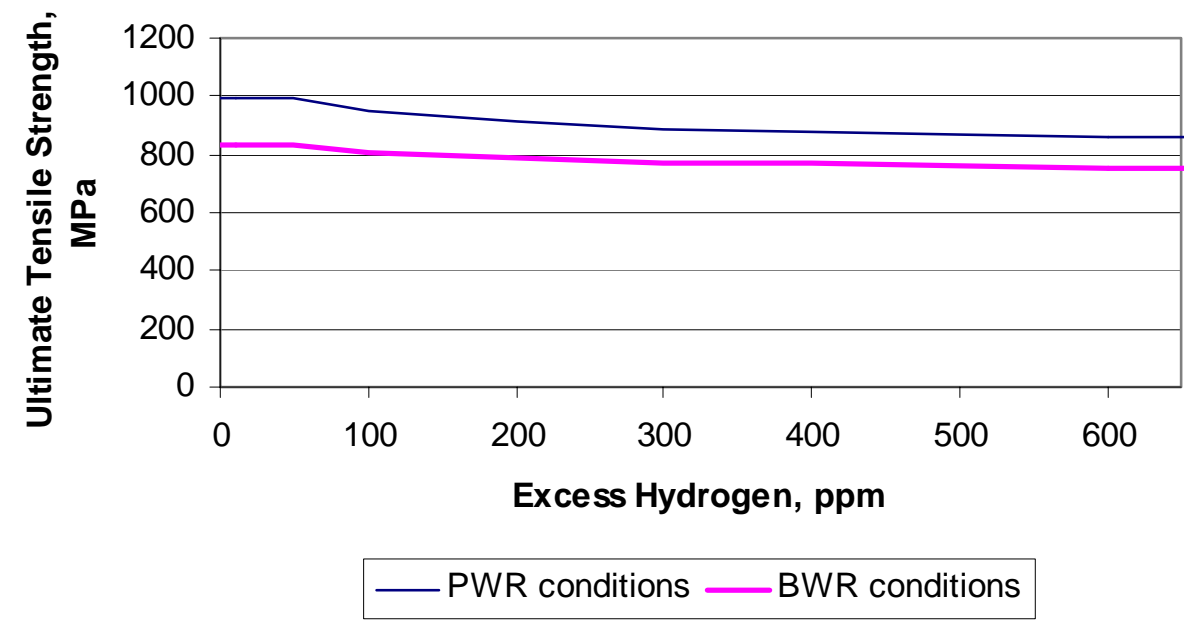

Figure 42: Model predictions of ultimate tensile strength for PWR and BWR conditions as a function of excess hydrogen for temperature of $300^{\circ} \mathrm{F}(422 \mathrm{~K})$ and strain rate of $1 \times 10^{-4} \mathrm{in} / \mathrm{in} / \mathrm{s}$ with other conditions given in Table 1 .

The uniform elongation model is only a function of temperature and hydrogen level. Therefore, Figures 43 and 44 present the predicted uniform elongation for PWR and BWR conditions as a function of temperature and excess hydrogen, respectively. The increase in uniform elongation seen in Figure 43 for the BWR conditions at $675 \mathrm{~K}$ is due to all the hydrogen going into solution at that point and the ductility increasing because of this. It should be noted that uniform elongation is not shown versus strain rate because this data is not currently available at high strain rate, i.e. $>1 \times 10^{-3} \mathrm{in} / \mathrm{in} / \mathrm{s}$. It is anticipated that there may be a decrease in uniform and total elongation at high strain rate because both yield and ultimate strength are shown to increase by 15 to $20 \%$ between strain rates of $10^{-3} \mathrm{in} / \mathrm{in} / \mathrm{s}$ and $1 \mathrm{in} / \mathrm{in} / \mathrm{s}$. This is because increases in Zircaloy cladding strength due to 
fluence and cold work both result in significant decreases in strain with total elongation having the largest decrease.

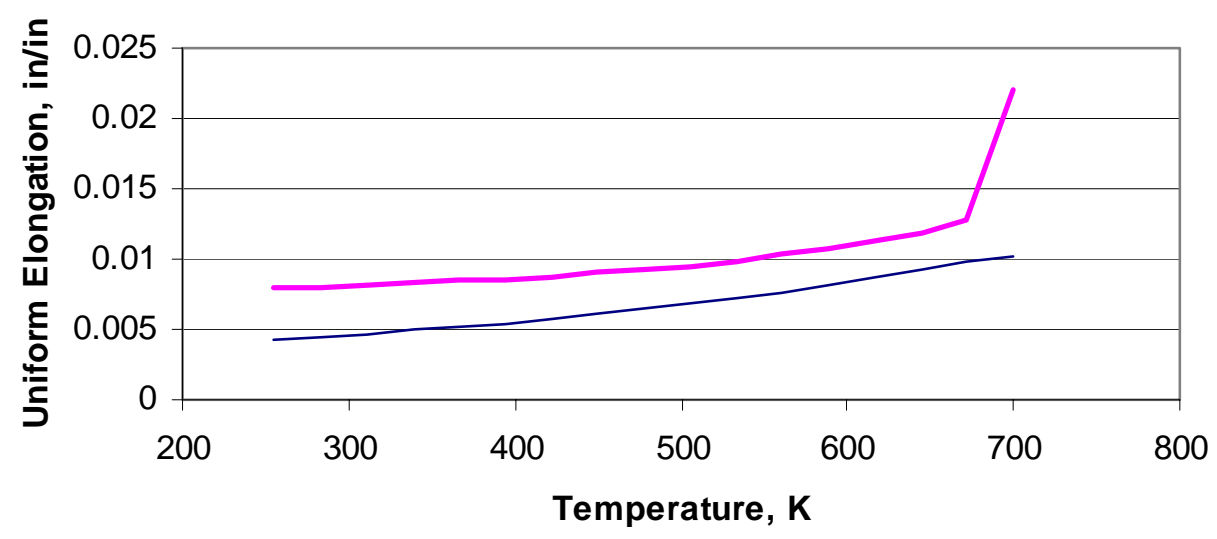

PWR conditions BWR conditions

Figure 43: Model predictions of uniform elongation for PWR and BWR conditions as a function of temperature for strain rate of $1 \times 10^{-4} \mathrm{in} / \mathrm{in} / \mathrm{s}$.

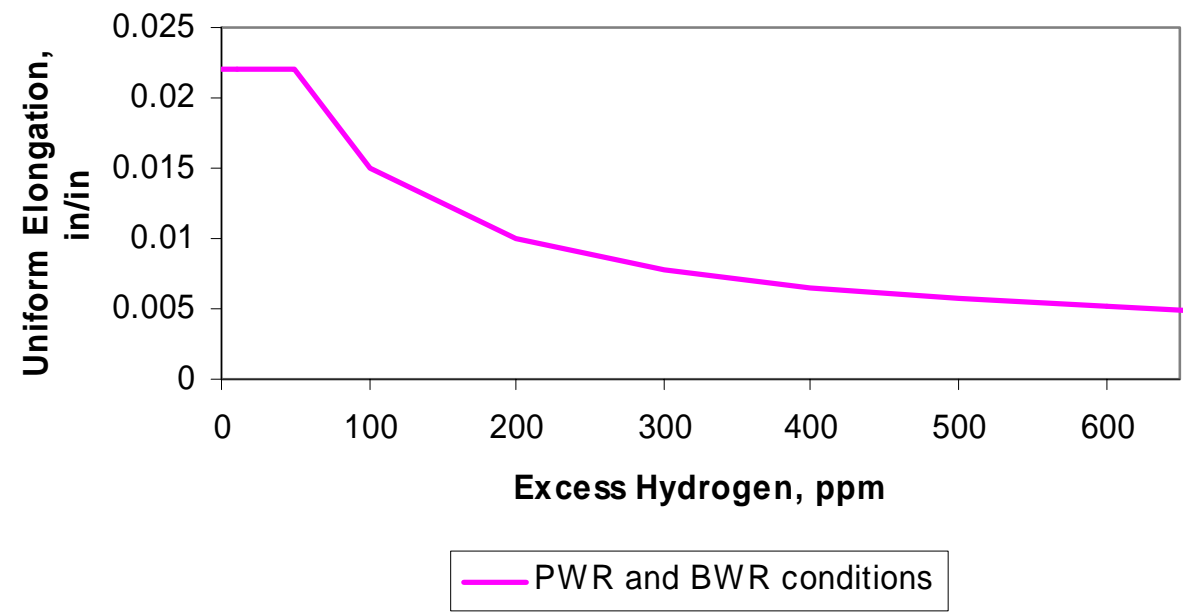

Figure 44: Model predictions of uniform elongation for PWR and BWR conditions as a function of excess hydrogen for temperature of $300^{\circ} \mathrm{F}(422 \mathrm{~K})$ and strain rate of $1 \times 10^{-4}$ in/in/s.

\section{Conclusions}

A new model (different from MATPRO) for stress/strain behavior of Zircaloy has been developed that adequately predicts the yield stress and ultimate tensile strength under uniaxial conditions for unirradiated and irradiated Zircaloy. The range of applicability for this model is listed in Table 2. This model was developed using data from axial tension tests and biaxial burst tests, and validated with data from ring stretch tests and more recent data from axial tensile tests and ring stretch tests. 
- The standard deviation in the difference between the model and the data from the three data sources is $67 \mathrm{MPa}$ and $70 \mathrm{MPa}$ for yield stress and ultimate tensile strength, respectively, for SRA Zircaloy.

- The model adequately predicts the uniform elongation for irradiated Zircaloy.

- These elastic-plastic models may not be applicable when hydrogen concentrations exceed $650 \mathrm{ppm}$, when oxide spallation has occurred because of local hydride blisters, when radial hydrides are present, or when strain rates are high $(>10 \mathrm{in} / \mathrm{in} / \mathrm{s})$. These conditions may cause brittle fracture that is not considered by these models.

- Due to the lack of RXA Zircaloy data, the uncertainty in the model predictions for RXA material should be assumed to be a factor of 2 higher than for SRA Zircaloy.

- The shape of the predicted stress/strain curve between the yield stress and ultimate tensile strength was compared to several measured stress/strain curves, and was found to reasonably predict the shape of the curve. It should be noted that due to the variation in yield stress, the curve may be shifted up or down, but in general the shape of the predicted stress/strain agrees well with the data.

Table 2. Range of applicability of mechanical property model

\begin{tabular}{|l|l|}
\hline Parameter & Range of Model Applicability \\
\hline Temperature & $293 \mathrm{~K}-1273 \mathrm{~K}$ \\
\hline Fast neutron fluence $(\mathrm{E}>1 \mathrm{MeV})$ & $0-1.4 \times 10^{26} \mathrm{n} / \mathrm{m}^{2}$ \\
\hline Cladding cold work & $0 \%-80 \%$ reduction in area \\
\hline Strain rate & $4 \times 10^{-3}-5 \mathrm{in} / \mathrm{in} / \mathrm{s}$ \\
\hline Excess hydrogen concentration & $\begin{array}{l}0-650 \mathrm{ppm} \text { (no spalled oxide or radial } \\
\text { hydrides) }\end{array}$ \\
\hline
\end{tabular}




\section{References}

1. G. A. Berna et al., "FRAPCON-3: A Computer Code for the Calculation of SteadyState, Thermal-Mechanical Behavior of Oxide Fuel Rods for High Burnup," NUREG/CR-6534, Vol. 1, PNNL-11513, Nuclear Regulatory Commission and Pacific Northwest National Laboratory (1997).

2. M. E. Cunningham el al., "FRAPTRAN: A Computer Code for the Transient Analysis of Oxide Fuel Rods," NUREG/CR-6739 Vol. 1, PNNL-13576, Nuclear Regulatory Commission and Pacific Northwest National Laboratory (2001).

3. A. M. Garde, "Hot Cell Examination of Extended Burnup Fuel From Fort Calhoun," DOE/ET/34030-11, U.S. Department of Energy and Combustion Engineering (1986).

4. M. G. Balfour, "Zorita Research and Development Program Volume 1, Final Report," WCAP-10180, Westinghouse Electric Corporation (1982).

5. C. G. Dideon and G. M. Bain, "Fuel Performance Under Extended-Burnup Operation B\&W 15x15 Design,” DOE/ET/34212-38, BAW-1716, U.S. Department of Energy and Babcock and Wilcox (1983).

6. L. W. Newman "The Hot Cell Examination of Oconee 1 Fuel Rods after Five Cycles of Irradiation," DOE/ET/34212-50, BAW-1874, U.S. Department of Energy and Babcock and Wilcox (1986).

7. L. W. Newman, "Development of an Extended Burnup Mark B Design," DOE/ET/34213-16, BAW 1532-13, U.S. Department of Energy and Babcock and Wilcox (1990).

8. G. P. Smith, "Hot Cell Examination of Extended Burnup Fuel from Calvert Cliffs-1," TR-103302-V2, ABB Combustion Engineering (1994).

9. G. P. Smith, "The Evaluation and Demonstration of Methods for Improved Nuclear Fuel Utilization, End-of-Cycles 6 and 7 Fuel Examinations," DOE/ET/34010-10, CEND-414, U.S. Department of Energy and C-E Power Systems (1983).

10. L. M. Lowry et al., "Evaluating Strength and Ductility of Irradiated Zircaloy, Task 5," NUREG/CR-1729, BMI-2066 Vol. 1, Nuclear Regulatory Commission and Battelle Columbus Laboratories (1981).

11. A. M. Garde, "Effects of Irradiation and Hydriding on the Mechanical Properties of Zircaloy-4 at High Fluence" Zirconium in the Nuclear Industry: 8th International Symposium, ASTM STP 1023, p. 548, American Society for Testing and Materials, Philadelphia, U.S.A. (1989). 
12. D. H. Hardy, "The Effect of Neutron Irradiation on the Mechanical Properties of Zirconium Alloy Fuel Cladding in Uniaxial and Biaxial Tests" Irradiation Effects on Structural Alloys for Nuclear Reactor Applications, ASTM STP 484, p. 215, American Society for Testing and Materials, Toronto, Canada (1970).

13. A. M. Garde et al., "Effects of Hydride Precipitate Localization and Neutron Fluence on the Ductility of Irradiated Zircaloy-4," Zirconium in the Nuclear Industry: 11th International Symposium, ASTM STP 1295, p. 407, American Society for Testing and Materials, Garmisch-Partenkirchen, Germany (1996).

14. R. S. Kemper and D. L. Zimmerman, "Neutron Irradiation Effects on the Tensile Properties of Zircaloy-2," HW-52323, General Electric Company (1957).

15. W. R. Smalley, "Saxton Core II Fuel Performance Evaluation Part I: Materials" WCAP 3385-56 Part 1, Westinghouse Electric Corporation (1971).

16. L. Berat-Robert et al., "Influence of a Zirconia Layer on the Mechanical Behavior of Zircaloy-4 Cladding and Thimble Tubes," LWR Fuel Performance Meeting, Vol. 2, p. 931, Park City, USA (2000).

17. R. Chun et al., "Dynamic Impact Effects on Spent Fuel Assemblies" UCID - 21246, Lawrence Livermore National Laboratory (1987).

18. S. T. Mahmood et al., "Effects of SPP Dissolution on Mechanical Properties of Zircaloy-2" LWR Fuel Performance Meeting, p. 440, Portland, U.S.A. (1997).

19. M.G. Balfour "High Burnup Fuel Rod Hot Cell Program, Vol. 1: Final Report," DOE/ET 34073-1, WCAP-10238, U.S. Department of Energy and Westinghouse Electric Corporation (1982).

20. S.K. Yagnik, A. Hermann, and R. C. Kuo "Ductility of Zircaloy-4 Fuel Cladding and Guide Tubes at High Fluences" Journal of ASTM International Vol. 2 [5] (2005)

21. K. Pettersson et al., "Effect of Irradiation on the Strength, Ductility, and Defect Sensitivity of Fully Recrystalized Zircaloy Tube", Zirconium in the Nuclear Industry, 4th conference, ASTM STP 681, p. 155 Stratford-upon-Avon, England (1979).

22. L. F. Van Swan, et al., "Behavior of Zircaloy-4 and Zirconium Liner Zircaloy-4 Cladding at High Burnup," LWR Fuel Performance Meeting, p. 421, Portland, USA (1997).

23. S.B. Wisner, R.B. Adamson, "Combined Effects of Radiation Damage and Hydrides on the Ductility of Zircaloy-2," Nuclear Engineering and Design, 185, 33 (1998).

24. M. C. Billone, "The Mechanical Properties Expert Group Update on Round Robin Test Results," Argonne National Laboratory (2002). 
25. M. Balourdet et al., "The PROMETRA Programme : assessment of mechanical properties of zircaloy-4 cladding during an RIA," SMIRT15 $-15^{\text {th }}$ International Conference on Structural Mechanics in Reactor Technology, Vol. II, p. 485, Seoul, Korea (1999).

26. A. Higdon et al., Mechanics of Materials, Fourth Edition, Chapter 9, John Wiley \& Sons, New York (1985).

27. D. L. Hagrman et al., "MATPRO - Version 11 (Revision 2) A Handbook of Materials Properties for Use in the Analysis of Light Water Reactor Fuel Rod Behavior," NUREG/CR-0479, TREE-1280, Nuclear Regulatory Commission and EG\&G (1981).

28. K. J. Geelhood et al., "Modifications to FRAPTRAN to Predict Fuel Rod Failures Due to PCMI during RIA-Type Accidents," Proceedings of the 2004 International Meeting on LWR Fuel Performance, Orlando, USA (2004).

29. C.D. Williams, R.B. Adamson, and K.D. Olshausen "Effects of Boiling Water Reactor Irradiation on Tensile Properties of Zircaloy", European Conference on Irradiation Behavior of Fuel Cladding and Core Component Materials, Karlsruhe pp. 189-102 (1974)

30. R. Onimus, J.L. Bechade, C. Prioul, et al. "Plastic Deformation of Irradiated Zirconium Alloys: TEM Investigations and Micromechanical Modeling” Journal of ASTM International Vol. 2 [8] (2005)

31. R. B. Adamson et at., "Failure Strain for Irradiated Zircaloy Based on Subsized Specimen Testing and Analysis," The Use of Small Scale Specimens for Testing Irradiated Material, ASTM STP 888, p. 171 (1986).

32. J. Desquines, B. Cazalis, C. Bernaudat, C. Poussard, X. Averty, and P.Yvon "Mechanical Properties of Zircaloy-4 PWR Fuel Cladding with Burnup 54$64 \mathrm{MWd} / \mathrm{kgU}$ and Implications for RIA Behavior" Journal of ASTM International Vol. 2 [6] (2005)

33. X.Averty, M. Genisson, J.P. Pizzanelli "PROMETRA-Tensile Tests on Ring Specimens Machined in Zirlo Cladding Irradiated 5 Cycles up to $75 \mathrm{GWd} / \mathrm{tU}$ " Institut De Radioprotection Et De Surete Nucleaire DMN/SEMI/LCMI/NT/2003-025/A, Sept. (2003). 